\title{
Protein nanocoatings on synthetic polymeric nanofibrous membranes designed as carriers for skin cells
}

\author{
Marketa Bacakova ${ }^{1,2}$ \\ Julia Pajorova ${ }^{1,2}$ \\ Denisa Stranska ${ }^{3}$ \\ Daniel Hadraba ${ }^{1,4}$ \\ Frantisek Lopot ${ }^{4}$ \\ Tomas Riedel ${ }^{5}$ \\ Eduard Brynda ${ }^{5}$ \\ Margit Zaloudkova ${ }^{6}$ \\ Lucie Bacakova' \\ 'Department of Biomaterials \\ and Tissue Engineering, Institute \\ of Physiology, Czech Academy \\ of Sciences, ${ }^{2}$ Second Faculty of \\ Medicine, Charles University, \\ Prague, ${ }^{3}$ InStar Technologies, \\ Liberec, ${ }^{4}$ Department of Anatomy \\ and Biomechanics, Faculty of \\ Physical Education and Sport, \\ Charles University, ${ }^{5}$ Department \\ of Chemistry and Physics of \\ Surfaces and Biointerfaces, Institute \\ of Macromolecular Chemistry, \\ ${ }^{6}$ Department of Composites and \\ Carbon Materials, Institute of Rock \\ Structure and Mechanics, Czech \\ Academy of Sciences, Prague, \\ Czech Republic
}

This article was published in the following Dove Press journal:

International Journal of Nanomedicine

9 February 2017

Number of times this article has been viewed
Abstract: Protein-coated resorbable synthetic polymeric nanofibrous membranes are promising for the fabrication of advanced skin substitutes. We fabricated electrospun polylactic acid and poly(lactide-co-glycolic acid) nanofibrous membranes and coated them with fibrin or collagen I. Fibronectin was attached to a fibrin or collagen nanocoating, in order further to enhance the cell adhesion and spreading. Fibrin regularly formed a coating around individual nanofibers in the membranes, and also formed a thin noncontinuous nanofibrous mesh on top of the membranes. Collagen also coated most of the fibers of the membrane and randomly created a soft gel on the membrane surface. Fibronectin predominantly adsorbed onto a thin fibrin mesh or a collagen gel, and formed a thin nanofibrous structure. Fibrin nanocoating greatly improved the attachment, spreading, and proliferation of human dermal fibroblasts, whereas collagen nanocoating had a positive influence on the behavior of human $\mathrm{HaCaT}$ keratinocytes. In addition, fibrin stimulated the fibroblasts to synthesize fibronectin and to deposit it as an extracellular matrix. Fibrin coating also showed a tendency to improve the ultimate tensile strength of the nanofibrous membranes. Fibronectin attached to fibrin or to a collagen coating further enhanced the adhesion, spreading, and proliferation of both cell types.

Keywords: skin-tissue engineering, nanocoating, nanofibers, skin cells, fibrin, collagen

\section{Introduction}

Advanced skin substitutes should mimic the morphology, composition, and functions of the original tissue. They have to accelerate tissue regeneration, ie, they have to support the formation of dermis and epidermis layers with a well-developed extracellular matrix (ECM). Moreover, they should enable nutrition supply and not cause unwanted immune reactions. However, clinically used skin substitutes have not yet met all these requirements, and they have several limiting factors. These substitutes mostly serve as temporary wound coverage or as carriers for skin cells, and ultimately they are rejected by the organism. ${ }^{1}$ This transplant rejection is caused mainly by the use of nonresorbable materials or allogenic cells that are subject to inflammatory reactions.

Advanced tissue engineering lays emphasis on the formation of two of the most important layers of natural skin: the dermis and the epidermis. Fibrous or porous membranes or films of nanoscale thickness can be advantageously used for developing a bilayer of fibroblasts and keratinocytes. The pores in the carriers can enable physical and biochemical communication between fibroblasts and keratinocytes. Moreover, the pores can ensure the supply of cells with active biological molecules, mainly with nutrients and growth factors from the cell culture medium or from the
Correspondence: Marketa Bacakova

Department of Biomaterials and Tissue Engineering, Institute of Physiology, Czech Academy of Sciences, 1083 Vídeňská, Prague 4 14220,

Czech Republic

Tel +420296443765

Email marketa.bacakova@fgu.cas.cz
International Journal of Nanomedicine 2017:12 || 43-| |60 (c) (1) (-) 2017 Bacakova et al. This work is published and licensed by Dove Medical Press Limited. The full terms of this license are available at https://www.dovepress.com/terms.php cC) and incorporate the Creative Commons Attribution - Non Commercial (unported, v3.0) License (http://creativecommons.org/licenses/by-nc/3.0/). By accessing the work you hereby accept the Terms. Non-commercial uses of the work are permitted without any further permission from Dove Medical Press Limited, provided the work is properly attributed. For permission for commercial use of this work, please see paragraphs 4.2 and 5 of our Terms (https://www.dovepress.com/terms.php). 
surrounding tissue. ${ }^{2}$ Nanostructured materials also mimic the nanofibrous component of the ECM in natural tissues better than conventional flat materials. ${ }^{3}$ They enable the adsorption of cell adhesion-mediating ECM molecules from body fluid or from cell culture media in an appropriate spatial orientation. This conformation of ECM molecules is important for binding their specific bioactive amino acid sequences by cell adhesion receptors, eg, integrins. ${ }^{4}$

Synthetic polymers or natural polymers have been used for constructing carriers for skin cells. ${ }^{5}$ However, these two types of materials are rarely applied in combination. Degradable synthetic polymers, mainly polyesters (polylactide, polylactide-co-glycolide, polycaprolactone), are relatively easily spinnable, eg, nanofibers can be formed by a process referred to as electrospinning. ${ }^{6}$ Moreover, nanofibrous membranes made of these synthetic polymers can provide stable mechanical support for cells. However, synthetic polymers in their pristine state are unable to provide sufficient support for cellular adhesion, proliferation, and deposition of an ECM. ${ }^{7,8}$ In these cases, synthetic polymers could be combined with molecules physiologically present in the skin, such as collagen, fibronectin, and hyaluronan, or with molecules occurring during wound healing, particularly fibrin. These molecules improve the colonization of matrices by cells. ${ }^{9}$ In addition, natural molecules, eg, fibrinogen as the precursor of fibrin, can be isolated in an autologous form from the patient's body fluids or tissues to prevent immune rejection of the implant. ${ }^{10}$

Collagen is an important component of the ECM in the skin dermis. It is mainly produced by fibroblasts and is organized into fibers running throughout the dermis. ${ }^{11}$ In skin substitutes, collagen is often applied in the form of a gel, ${ }^{12,13}$ or it is used in composites with other natural or synthetic materials. ${ }^{14,15}$ Previous studies have revealed that collagen supports wound healing. Niiyama and Kuroyanagi combined collagen with hyaluronic acid and functionalized this composite with EGF. ${ }^{16}$ Butler and Orgill observed improved growth of epidermal keratinocytes on a collagenglycosaminoglycan matrix. ${ }^{17}$ Wang et al prepared collagen/ chitosan-based scaffolds with VEGF and gentamicin encapsulated into poly(lactide-co-glycolic acid) (PLGA) microspheres and observed positive effects of these scaffolds on the adhesion and growth of mouse fibroblasts. ${ }^{18}$ Collagen has also been widely applied in clinically used skin substitutes. For example, Integra (Integra LifeSciences, Plainsboro, NJ, USA), which is used for treating severe fullthickness burns, consists of a silicone layer on top of a porous matrix comprising a chemically cross-linked coprecipitate of bovine collagen and shark-derived chondroitin-6-sulfate. The pore size of 20-125 $\mu \mathrm{m}$ allows ingrowth of fibroblasts and revascularization. After that, keratinocytes can be applied on the material surface. Apligraf (Organogenesis Inc, Canton, MA,USA) is a bilayered skin substitute used for treating venous ulcers, diabetic ulcers, donor-site wounds, epidermolysis bullosa, and cutis aplasia. Apligraf consists of allogeneic neonatal fibroblasts cultivated on a bovine type I collagen matrix. Keratinocytes are cultured on the top of this dermal layer. ${ }^{19,20}$

Fibrin is a provisional matrix molecule that plays an important role during wound healing. Fibrin fibers are formed from fibrinogen, a soluble precursor, in the last step of the coagulation cascade. ${ }^{21}$ Cells can bind directly to fibrin(ogen) via integrin cell adhesion receptors or via nonintegrin receptors (eg, VE-cadherin, ICAM1, or P-selectin). Fibrin is also able to bind cell adhesion-mediating proteins (eg, fibronectin and vitronectin) or growth factors. ${ }^{22}$ Fibrin has often been applied in the form of a glue, gel, or microbeads. ${ }^{23-25}$ For better regenerative potential and mechanical stability, fibrin matrices have been combined with other biological or synthetic molecules, eg, collagen, ${ }^{26,27}$ hyaluronic acid with a cell adhesion-promoting peptide, ${ }^{28}$ basic $\mathrm{FGF},{ }^{29}$ or EGF. ${ }^{30}$ Fibrin has relatively rarely been deposited on supporting substrates, although fibrin selfsupporting matrices are usually fragile. In our previous study, we deposited a fibrin nanocoating on polylactide nanofibrous membranes and observed its positive influence on the behavior of dermal fibroblasts. ${ }^{9}$ Fibrin has also been used in commercially available skin substitutes. For example, ICX-SKN (Intercytex, Manchester, UK), a fibrin matrix seeded with neonatal human fibroblasts, is promising for ulcer treatment. ${ }^{20}$

In our study, we prepared electrospun polylactic acid (PLA) and PLGA nanofibrous membranes, coated them with fibrin or collagen I, and then with fibronectin attached to the surface of these proteins. Firstly, we compared the behavior of human dermal fibroblasts and human $\mathrm{HaCaT}$ keratinocytes on these two protein-modified biodegradable polymer matrices. Although the physical and chemical properties and the biocompatibility of PLA and PLGA are generally considered very close, some differences have been reported between these polymers as regards their degradability, mechanical integrity, ${ }^{31}$ porosity, wettability, protein adsorption, ${ }^{32}$ and cell behavior on their surfaces; ${ }^{33,34}$ therefore, differences in cell adhesion and growth for these polymers were also expected in this study. Secondly, we evaluated the influence of newly developed protein nanocoatings, 
ie, fibrin, collagen, and fibronectin, on the adhesion and growth of dermal fibroblasts and $\mathrm{HaCaT}$ keratinocytes on the nanofibrous PLA and PLGA scaffolds.

\section{Materials and methods Preparation of nanofibrous membranes}

Experiments were carried out on nanofibrous membranes made of a PLGA copolymer (ratio 85:15, Purasorb ${ }^{\circledR}$ PLG 8531; Corbion, Amsterdam, the Netherlands) or made of PLA (Ingeo ${ }^{\mathrm{TM}}$ Biopolymer 4032D; NatureWorks, Minnetonka, MN, USA). The solution for the polymers was prepared and the electrospinning process carried out as presented in our previous work. ${ }^{9}$ Both polymers were dissolved in chloroform. Solvents - dichloroethane and ethyl acetate - were added into a PLA solution to a final concentration of $7 \mathrm{wt} \%$ of PLA. The volume ratio of the chloroform, dichloroethane, and ethyl acetate solvents was 61:29:10. The solution of the two polymers was made electrically conductive with the use of tetraethylammonium bromide. This chemical was first dissolved in dimethylformamide to a concentration of $3 \mathrm{wt} \%$. Then, $3 \mathrm{~g}$ of this solution was added to $100 \mathrm{~g}$ of the PLGA or PLA solution.

Nanospider needle-free electrospinning technology (Elmarco, Liberec, Czech Republic) was used for preparing the nanofibrous membranes. The process conditions were electrode distance $145-180 \mathrm{~mm}$, voltage $50-60 \mathrm{kV}$, relative humidity $20 \%-30 \%$, and room temperature. Fiber density, ie, the area weight of the prepared nanofibers, was $10.5-19.6 \mathrm{~g} / \mathrm{m}^{2}$ for PLGA and $13-15 \mathrm{~g} / \mathrm{m}^{2}$ for PLA. The thickness of the membranes was in the range of 47-97 $\mu \mathrm{m}$ for PLGA and 125-190 $\mu \mathrm{m}$ for PLA. ${ }^{9}$

\section{Preparation of fibrin and collagen nanocoating with attached fibronectin}

The fibrin nanocoating on the polymeric nanofibrous membranes was formed by activating human fibrinogen (341576; EMD Millipore, Billerica, MA, USA) with human thrombin (T6884; Sigma-Aldrich Co, St Louis, MO, USA), as described in detail in our previous papers. ${ }^{9,35}$ Fibrinogen at a concentration of $10 \mu \mathrm{g} / \mathrm{mL}$ in Tris buffer (consisting of $50 \mathrm{mM}$ Tris- $\mathrm{HCl}, 100 \mathrm{nM} \mathrm{NaCl}$, and $2.5 \mathrm{mM} \mathrm{CaCl}_{2}$ ) was adsorbed on the membrane surface for 1 hour. After being rinsed with Tris buffer, the adsorbed fibrinogen was activated with thrombin ( $2.5 \mathrm{U} / \mathrm{mL}$ in Tris buffer) for 15 minutes. The samples were rinsed with Tris buffer, and a solution of $200 \mu \mathrm{g} / \mathrm{mL}$ of fibrinogen in Tris buffer and $0.5 \mathrm{U} / \mathrm{mL}$ of antithrombin III in deionized water was added to the membranes for 1 hour. A fibrin network was formed by a catalytic reaction of the surface-attached thrombin with the ambient fibrinogen solution. The antithrombin III blocked the unreacted thrombin, in order to form a 2-D fibrin layer (Figure 1).

The collagen nanocoating was formed from a collagen solution by changing the $\mathrm{pH}$. The collagen solution (rat tail, $3.37 \mathrm{mg} / \mathrm{mL}$; Corning Incorporated, Corning, NY, USA) was diluted in $0.02 \mathrm{M}$ acetic acid to a final concentration of $200 \mu \mathrm{g} / \mathrm{mL}$, and was applied to the samples. The samples were immersed in ammonia vapor for 10 minutes to change the acid $\mathrm{pH}$ to basic $\mathrm{pH}$. After collagen precipitation, the solution was sucked out and the samples rinsed with deionized water (Figure 1).

Fibronectin was attached to the surface of the fibrin and collagen nanocoating. Fibronectin powder (human, 11051407001; Hoffman-La Roche Ltd, Basel, Switzerland) was dissolved in deionized water at a concentration of $1 \mathrm{mg} / \mathrm{mL}$. The fibronectin solution was subsequently diluted in phosphate-buffered saline (PBS; Sigma-Aldrich) to a final concentration of $50 \mu \mathrm{g} / \mathrm{mL}$ and incubated with the samples overnight at $4^{\circ} \mathrm{C}$. The samples were then rinsed twice with PBS.

\section{Morphology of nanofibrous membranes}

The morphology of the PLGA and PLA nanofibrous membranes in their pristine state (ie, uncoated membranes) was studied by scanning electron microscopy (SEM). The measurements were carried out in accordance with a previously published protocol: ${ }^{9}$ the membranes were sputtercoated with gold and evaluated by SEM (Quanta 450; Thermo Fisher Scientific, Waltham, MA, USA) in high vacuum mode. The images were taken using an Everhart-Thornley detector in secondary electron mode at high voltage $(20 \mathrm{kV})$ and magnification $2,000 \times$ and $10,000 \times$. The thickness of the membranes was determined from SEM images of a vertical section of the membrane. The diameter of the fibers was measured on the SEM images using Atlas software (Tescan, Brno, Czech Republic).

\section{Membrane puncture testing}

Nanofibrous membranes in CellCrown inserts $(n=6$ for each group of scaffolds; Scaffdex Oy, Tampere, Finland) were placed into the manufactured holder and secured against a tilt. Then, the holder was fastened in the standard microscope stage (DM2500; Leica Microsystems, Wetzlar, Germany) and the microscope condenser replaced with a manufactured tooling that carried a low-level force sensor (9203; Kistler, Winterthur, Switzerland) with a spherical cup 

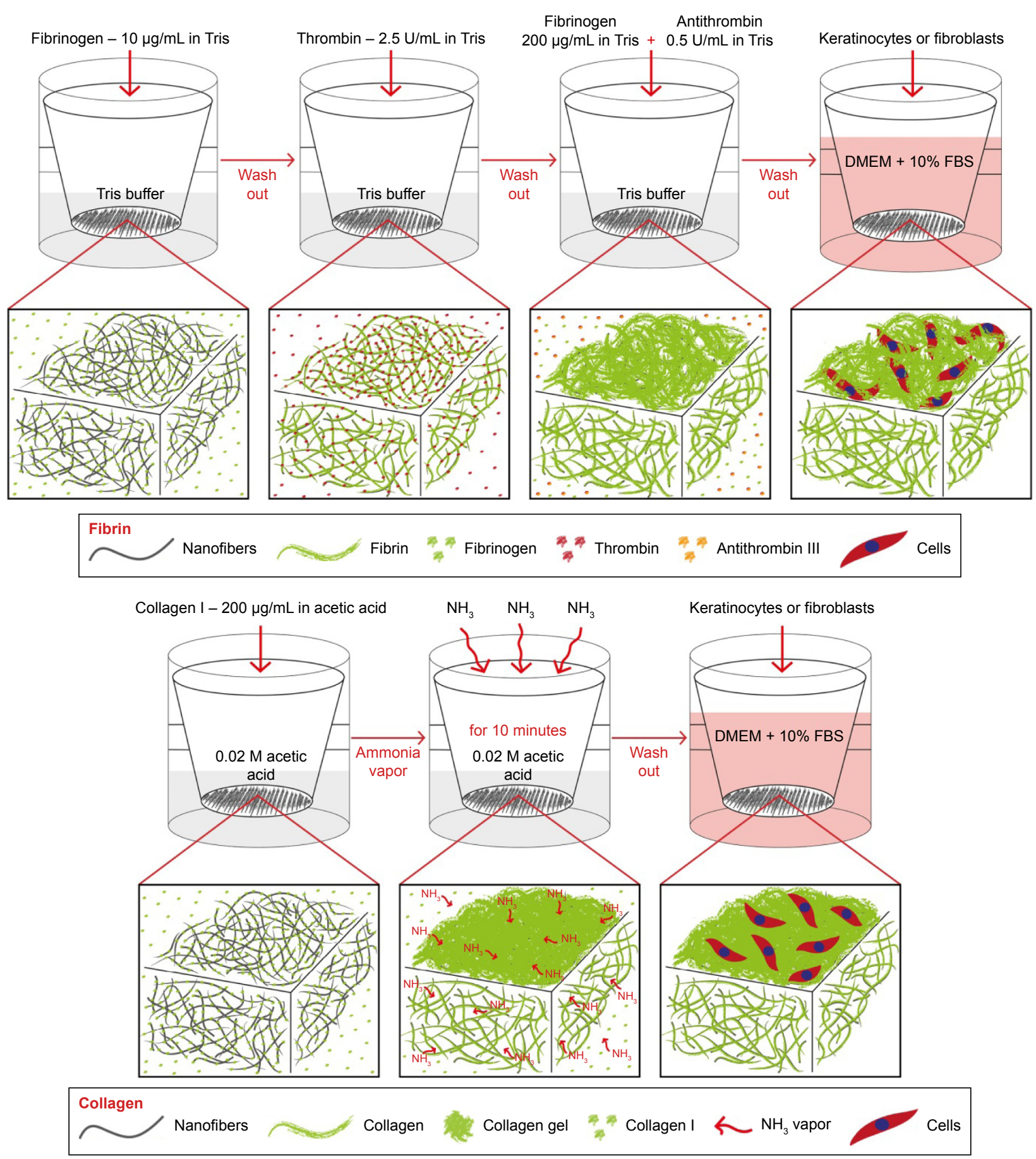

Figure I Schematic representation of a preparation of fibrin and collagen nanocoating on nanofibrous membrane.

Abbreviations: FBS, fetal bovine serum; DMEM, Dulbecco's Modified Eagle's Medium.

probe (Figure 2). Due to the construction of the DM2500 microscope, the force sensor can be moved independently on the stage in respect to the focal plane. First, the membranes were focused and imaged by the confocal microscope (magnification $4 \times$, image resolution $1,024 \times 1,024$, pixel size $1.8 \mu \mathrm{m})$ to verify their structural integrity. Second, the camera started capturing the calibrated images (image resolution $1,920 \times 1,440$, pixel size $0.05 \mathrm{~mm}$ ) of the membrane at
$10 \mathrm{~Hz}$ repetition rate, and the force sensor recorded the force changes at $100 \mathrm{~Hz}$ repetition rate. Finally, the force sensor with the probe moved toward the sample at a speed of $0.2 \mathrm{~mm} / \mathrm{s}$ until the force value returned to zero.

The deformation $u_{z}$ of the nanofibrous membranes was evaluated in MatLab 2015A (MathWorks, Natick, MA, USA) by image segmentation (thresholding and edge detection using a Sobel filter). The stress in the membrane $\sigma_{t}$ is based 


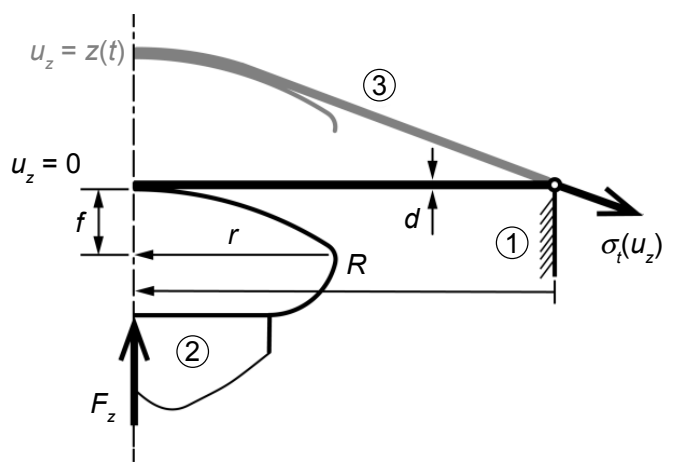

Figure 2 The puncture testing protocol.

Notes: The CellCrown membrane insert (1) with radius $R$ represents the pinned joint. The probe (2) with radius $r$ and head-high $f$ deforms the membrane (3) of measured thickness $d$ until rupture. The dimensions are used to calculate the membrane stress $\sigma_{t}$.

on static equilibrium, and calculated from the force data $F_{z}$ and deformation $u_{z}$ as

$$
\sigma_{t}\left(u_{z} \leq a\right)=\frac{F_{z}}{2 \pi R d \tan ^{-1}\left(\frac{R}{u_{z}}\right)}
$$

or

$$
\sigma_{t}\left(u_{z}>a\right)=\frac{F_{z}}{2 \pi R d \tan ^{-1}\left(\frac{R-r}{u_{z}-f}\right)}
$$

for the geometrical contact ratio $a$ :

$$
a=\frac{f}{r} R
$$

\section{Cell culture}

The nanofibrous membranes were fixed in CellCrown inserts, in order to prevent them floating in the cell culture medium, and inserted into the wells of 24-well plates (well diameter $1.56 \mathrm{~cm}$; TPP Techno Plastic Products AG, Trasadingen, Switzerland). Samples were seeded with neonatal human dermal fibroblasts, purchased from Lonza (Basel, Switzerland), passage 3-6, or with human keratinocytes of the line HaCaT, purchased from CLS Cell Lines Service (Eppelheim, Germany). ${ }^{36}$ The HaCaT cell line consists of spontaneously transformed and immortal human epidermal keratinocytes, but it remains nontumorigenic and maintains full epidermal differentiation capacity. In contrast to normal keratinocytes, $\mathrm{HaCaT}$ cells are able to adhere to various materials without requiring a fibroblast feeder layer for their adhesion and growth. This property of $\mathrm{HaCaT}$ cells can be regarded as advantageous for studies on the suitability of various synthetic and biological scaffolds for skin tissue engineering and was also used for this purpose in our study.

Cells were seeded at a density of approximately 10,000 cells $/ \mathrm{cm}^{2}$ (ie, 20,000 cells/well) and were cultivated in Dulbecco's Modified Eagle's Medium (Sigma-Aldrich) with $10 \%$ of fetal bovine serum (Sebak $\mathrm{GmbH}$, Aidenbach, Germany) and $40 \mu \mathrm{g} / \mathrm{mL}$ of gentamicin (Novartis International AG, Basel, Switzerland). The volume of cell culture medium was $1.5 \mathrm{~mL} /$ well. Cells were cultivated for three time periods $\left(1,3\right.$, and 7 days) in a cell incubator at $37^{\circ} \mathrm{C}$ and in a humidified atmosphere with $5 \% \mathrm{CO}_{2}$. Polystyrene culture wells (24-well plates) were used as a control material.

\section{Morphology of protein nanocoatings}

The morphology of the fibrin, collagen, and fibronectin nanocoatings was studied by immunofluorescence staining on freshly prepared samples, on cell-free samples incubated for two periods (ie, on days 3 and 7) in Dulbecco's Modified Eagle's Medium under the conditions used for cell cultivation, and on samples with cells on days 3 or 7 after seeding. Uncoated membranes were used as control samples to evaluate possible nonspecific binding of the primary and secondary antibodies. Two samples of each experimental group for each time period were used.

The membranes were treated with $1 \%$ bovine serum albumin in PBS for 20 minutes, and then with 1\% Tween (Sigma-Aldrich Co) in PBS for 20 minutes at room temperature to block nonspecific binding sites. The samples were subsequently incubated overnight at $4^{\circ} \mathrm{C}$ with primary antibodies against human fibrinogen (polyclonal rabbit antibody; Dako Denmark A/S, Glostrup, Denmark), collagen I (monoclonal mouse antibody; Sigma-Aldrich), or fibronectin (monoclonal mouse antibody; Sigma-Aldrich) diluted in PBS at a ratio of 1:200. The samples were then rinsed twice with PBS and incubated with secondary antibodies, namely goat antirabbit or goat antimouse $\mathrm{F}\left(\mathrm{ab}^{\prime}\right)_{2}$ fragments of $\operatorname{IgG}(\mathrm{H}+\mathrm{L}$ [Heavy and Light chains]), conjugated with Alexa Fluor ${ }^{\circledR} 488$ (diluted in PBS at a ratio of 1:400; Thermo Fisher Scientific) for 1 hour at room temperature in the dark.

The fibrin- or collagen-coated membranes with attached fibronectin were also stained for fibrin + fibronectin or collagen + fibronectin on the same sample. The samples were incubated overnight at $4^{\circ} \mathrm{C}$ with primary antibodies against human fibrinogen (rabbit polyclonal antibody; Dako) or with collagen I (rabbit polyclonal antibody; Cosmo Bio Co Ltd, Tokyo, Japan) diluted in PBS at a ratio of 1:200. 
Subsequently, after being rinsed with PBS, the primary antibody against fibronectin (mouse monoclonal antibody; Sigma-Aldrich) was added for 3 hours. The samples were rinsed with PBS and incubated with a secondary antibody goat antirabbit $\mathrm{F}\left(\mathrm{ab}^{\prime}\right)_{2}$ fragment of $\operatorname{IgG}(\mathrm{H}+\mathrm{L})$, conjugated with Alexa Fluor 488 (diluted in PBS at a ratio of 1:400) for 1 hour (in order to visualize the fibrin or collagen), and then with a secondary antibody goat antimouse $\mathrm{F}\left(\mathrm{ab}^{\prime}\right)_{2}$, fragment of $\operatorname{IgG}(\mathrm{H}+\mathrm{L})$, conjugated with Alexa Fluor 633 (diluted in PBS at a ratio of 1:400) for 1 hour (in order to visualize the fibrinogen). The samples were rinsed with PBS and scanned using the Leica TCS SPE DM2500 upright confocal microscope, magnification $40 \times / 1.15$ NA oil.

\section{Cell spreading and morphology}

The spreading and morphology of the cells on uncoated or protein-coated nanofibrous membranes were visualized on days 1,3 , and 7 after seeding by staining the cells with a combination of fluorescent dyes diluted in PBS $(5 \mu \mathrm{g} / \mathrm{mL}$ Hoechst 33258 cell nucleus dye; Sigma-Aldrich; and $20 \mathrm{ng} / \mathrm{mL}$ Texas red $\mathrm{C}_{2}$-maleimide cell membrane dye; Thermo Fisher Scientific) for 1 hour at room temperature in the dark. Instead of Texas red staining, the F-actin cytoskeleton of the cells was stained with phalloidin conjugated with tetramethylrhodamine isothiocyanate fluorescent dye (Sigma-Aldrich), diluted in PBS to a final concentration of $5 \mu \mathrm{g} / \mathrm{mL}$, for 1 hour at room temperature in the dark. Before staining, the cells were rinsed with $\mathrm{PBS}$ and were fixed with $-20^{\circ} \mathrm{C}$ cold ethanol for 10 minutes. Images of the cells were taken using epifluorescence microscopy (magnification 10×, IX 51; Olympus, Tokyo, Japan) equipped with a digital camera (DP 70), or using the Leica TCS SPE DM2500 upright confocal microscope, magnification $40 \times / 1.15$ NA oil. On day 1 after seeding of the cells, the spreading area of islands formed by human $\mathrm{HaCaT}$ keratinocytes was measured on images taken under fluorescence microscopy using the Atlas software.

\section{Cell mitochondrial activity}

The activity of mitochondrial enzymes was measured at three points of cell cultivation (on days 1, 3, and 7 after cell seeding) for the dermal fibroblasts and at two points (on days 3 and 7 after cell seeding) for the $\mathrm{HaCaT}$ keratinocytes with CellTiter $96^{\circledR}$ Aqueous One solution cell proliferation assay (MTS; Promega Corporation, Fitchburg, WI, USA) on samples of nanofibrous membranes incubated in 24-well cell culture plates. The mitochondrial activity of the HaCaT keratinocytes was measured only on days 3 and 7, but not on day 1 after cell seeding. The reason was that our preliminary measurements, using the MTS assay, revealed that on day 1 after seeding, when cell numbers were relatively low, the measured absorbance was on the limit of detection and showed no significant differences among the tested samples. This was probably due to the relatively low activity of the mitochondrial enzymes in the HaCaT cells. In cell culture and human skin sections, the activities of mitochondrial enzymes were lower in keratinocytes than in fibroblasts. ${ }^{37}$ The principle of an MTS assay is based on cleavage of the yellow tetrazolium salt MTS and on the formation of a watersoluble brown formazan salt by the activity of mitochondrial enzymes (ie, dehydrogenases) in the cells. The formazan dye produced by the cells was then quantified by measuring the absorbance using a spectrophotometer (ie, an enzyme-linked immunosorbent assay [ELISA] reader).

Membrane samples were moved into fresh 24-well plates to avoid the influence of the cells adhered to the bottom of the well. The assay was performed according to the manufacturer's protocol. Absorbance was measured using the VersaMax ELISA microplate reader (Molecular Devices LLC, Sunnyvale, CA, USA) in Nunc-Immuno MicroWell 96-well cell culture plates (Sigma-Aldrich) with wavelength $490 \mathrm{~nm}$. Three independent samples for each experimental group and time point were used. One sample without cells for each experimental group and time point was used as a control to set the background for the measured absorbance. A polystyrene culture dish (24-well plate) was used as a control material for the cell mitochondrial activity.

\section{Cell viability}

The cell viability was determined using a Live/Dead viability/ cytotoxicity kit (Thermo Fisher Scientific). The principle of this assay is based on the different ability of two fluorescent dyes to penetrate the cell membrane of live and dead cells. Calcein AM penetrates live cells, where it is converted by esterases to calcein, which emits green fluorescence. Ethidium homodimer 1 penetrates the membrane of the dead cells and stains them with red fluorescence.

The samples were carefully rinsed with PBS and stained with a solution of $2 \times 10^{-3} \mu \mathrm{M}$ calcein $\mathrm{AM}$ and $6 \times 10^{-3} \mu \mathrm{M}$ ethidium homodimer 1 . After 10 minutes of incubation in the cell incubator, the cells were rinsed with PBS and evaluated using epifluorescence microscopy (IX 51) equipped with a digital camera (DP 70).

\section{Statistics}

Quantitative data are presented as mean \pm standard deviation values or standard error of the mean from three independent 
samples for each experimental group and time point. Statistical significance was evaluated using analysis of variance, Student-Newman-Keuls method or nonparametric Kruskal-Wallis test, and Mann-Whitney $U$ test. Values of $P \leq 0.05$ were considered significant.

\section{Results}

\section{Morphology and mechanical properties of nanofibrous membranes}

Fibers of both types of nanofibrous membranes were mostly straight and randomly oriented. The diameter of the fibers was within a large range, from tens of nm to more than $1 \mu \mathrm{m}$. The average fiber diameter was more than $300 \mathrm{~nm}$ (Figure 3), similarly to our earlier study. ${ }^{9}$ The material nanostructures were defined to be equal to or less than $100 \mathrm{~nm}$ in at least one dimension. The fiber diameter in our study was thus in submicron and micron scale rather than in nanoscale. However, such fibers are frequently referred to in the literature as nanofibers. ${ }^{4,38-40}$

Puncture testing revealed a faster mechanical response of the PLA membranes. At about $1 \mathrm{~mm}$ deformation, the stress/strain direction changed dramatically and the PLA response stayed linear until rupture. On the other hand, the PLGA membranes reacted to loading gradually and reached significantly lower ultimate strength than the PLA groups (Mann-Whitney $U$ test, $P=0.032$ ). After collagen modification, the membranes seemed to become brittle. Fibrin modification caused an upward trend in ultimate strength. However, there was no significant difference in ultimate strength when comparing all the modifications (Kruskal-Wallis test, $P=0.177$ ) (Figure 4, Table 1).
Morphology of protein nanocoating and its stability and degradation during cell cultivation

Fibrin regularly formed a coating around individual nanofibers, and also formed a thin nanofibrous mesh on the membrane surface. However, this mesh did not form homogeneously on the whole surface of the membrane. Collagen also coated most of the fibers in the membranes, but not regularly. Moreover, collagen randomly formed a soft gel on the membrane surface (Figure 5). Fibronectin was bound on the fibrin and collagen nanocoating. Fibronectin formed an additional nanofibrous mesh on the thin fibrin mesh or on the collagen gel (Figure 6). Fibronectin also adsorbed on fibers coated with fibrin or collagen, but it was hardly visible using immunofluorescence. There was no apparent difference in the morphology of the protein nanocoating on PLGA and PLA membranes (Figure 5).

The durability of the protein nanocoatings on the nanofibrous membranes was tested during 7 days under the same conditions as those used for cell cultivation. The results showed that the fibrin, collagen, or fibronectin nanocoatings on both polymer membranes were stable in a cell-free environment, and their morphology was almost unchanged after 1 week (Figure 5).

However, the cells altered the morphology of the protein nanocoatings during their cultivation. Both types of cells degraded and reorganized the protein nanocoating (Figure 7). Fibroblasts penetrated into the fibrin mesh and gradually degraded the fibrin nanocoating. Nevertheless, on day 7 , some fibrin-coated fibers and some remains of the thin fibrin nanofibrous mesh were still apparent. Collagen was less degraded than fibrin by fibroblasts. However, the collagen
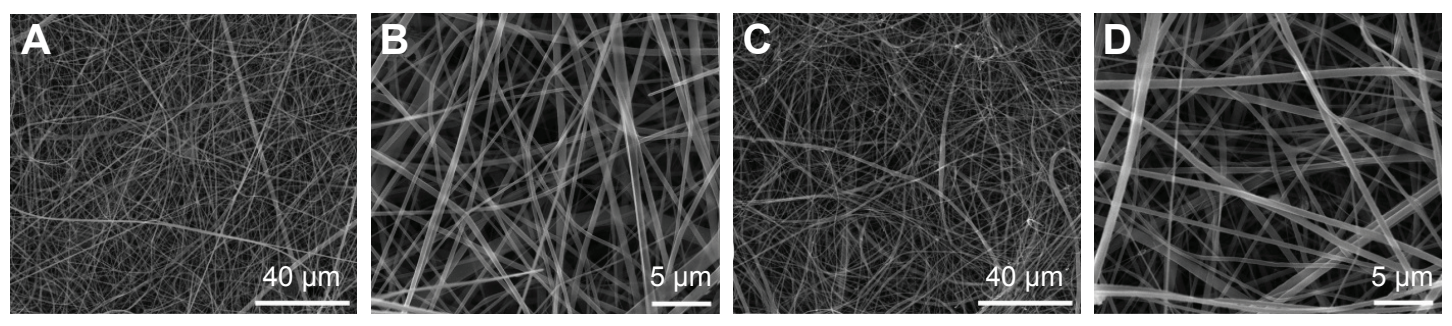

E

\begin{tabular}{|l|l|l|}
\hline & PLGA & PLA \\
\hline Fiber density $\left(\mathrm{g} / \mathrm{m}^{2}\right)$ & $10.5-19.6$ & $13-15$ \\
\hline Membrane thickness $(\mu \mathrm{m})$ & $47-97$ & $125-190$ \\
\hline Fiber diameter, mean $\pm \mathrm{SD}(\mathrm{nm})$ & $341 \pm 203$ & $352 \pm 205$ \\
\hline Fiber diameter range $(\mathrm{nm})$ & $28-2,054$ & $41-1,747$ \\
\hline
\end{tabular}

Figure 3 SEM images of unmodified PLGA membranes (A, B) and PLA membranes (C, D).

Notes: Quanta 450 scanning electron microscope, original magnification 2,000× (A, C) or 10,000× (B, D). Morphological parameters of PLGA and PLA membranes (E). Fiber diameter: mean \pm SD from I 2 SEM images ( I,748 measurements in total).

Abbreviations: SEM, scanning electron microscopy; PLGA, poly(lactide-co-glycolic acid); PLA, polylactic acid; SD, standard deviation. 

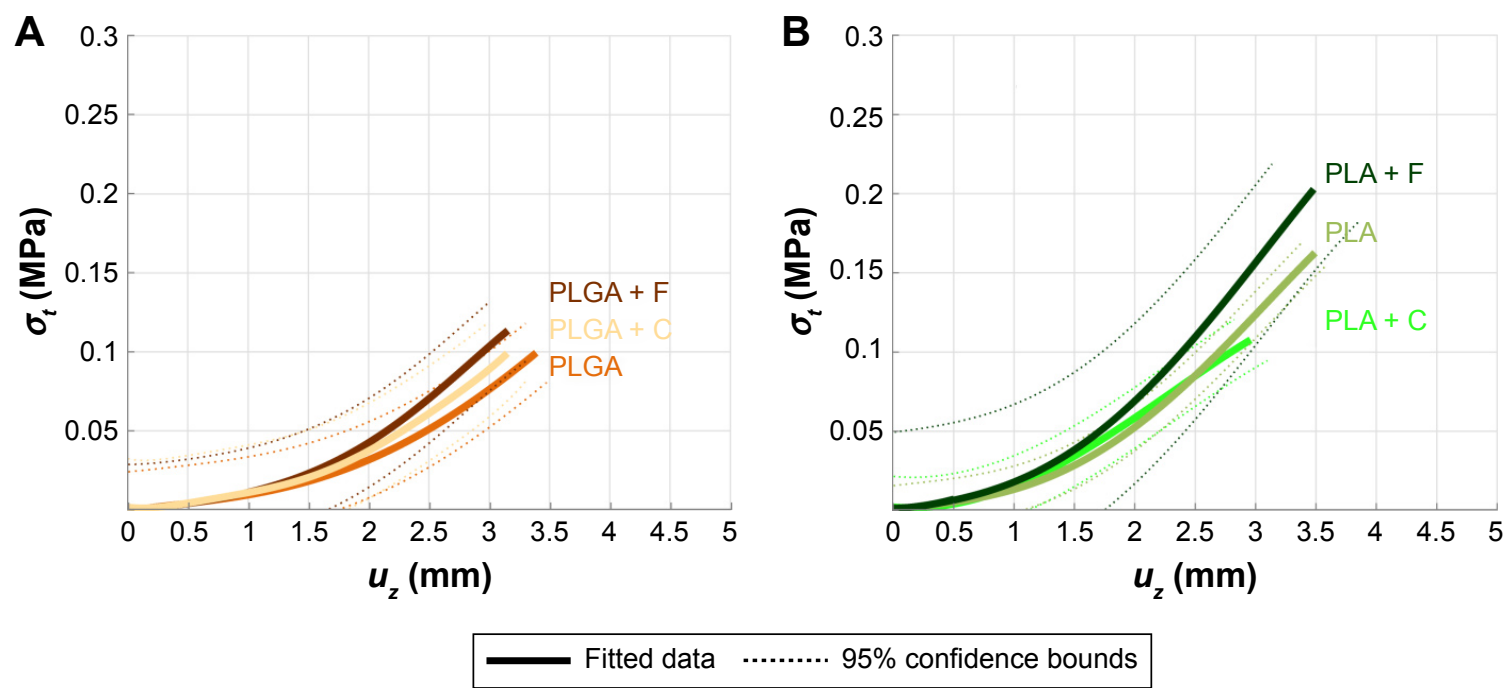

Figure 4 Puncture mechanical testing.

Notes: The membrane's mechanical response was plotted for the unmodified PLGA (A) or PLA (B) membrane and for each modification of the membranes as a polynomial up to the maximum mean values of stress and strain (thick colored line) and as the confidence bounds of the fit (thin dashed line).

Abbreviations: PLGA, poly(lactide-co-glycolic acid); PLA, polylactic acid; F, fibrin; C, collagen.

gel that formed on the membrane surface appeared to be too soft for the adhesion and growth of fibroblasts, and the cells were often detached from the surface of the material. The fibronectin mesh degraded faster on the fibrin nanocoatings than on the collagen nanocoatings. In addition, the fibrincoated membranes apparently stimulated the fibroblasts to produce fibronectin and to deposit it as ECM in the cell surroundings (Figure 8).

$\mathrm{HaCaT}$ keratinocytes degraded the protein nanocoating in a different way. Thin nanofibrous fibrin and fibronectin meshes on the fibrin-coated membranes were almost completely degraded on day 3 after seeding. Only fibers coated with fibrin and the remains of fibronectin meshes remained until day 7 of seeding. The degradation process had started already on day 1 of cell cultivation (data not shown here). In Figure 7, it is apparent that the keratinocytes adhered on the membrane surface did not penetrate the membrane, but remained on the surface of the fibrin or fibronectin meshes, and these meshes were pulled down, probably by cell traction forces. Surprisingly, the fibronectin attached to the collagen gel was not degraded in a similar manner as the fibronectin on the fibrin. The fibronectin attached to the collagen, and also the collagen itself, was only slightly changed and degraded after 7 days of cell cultivation.

\section{Cell adhesion, spreading, and morphology}

Differences in cell morphology among the various types of samples and cells were observed. On the coated samples, the fibroblasts were well spread with a spindle-like or polygonal shape already on day 1 after cell seeding. However, on the uncoated membranes, the cells tended to be round and not well adhered (Figure 9). After 1 week of cell cultivation, the fibroblasts on the fibrin-coated samples, and also on the collagen-coated samples, were almost confluent. On the uncoated membranes, however, there were considerably large free spaces among the cells. On the membranes with fibrin, the cells were able to penetrate into the fibrin mesh and into deeper layers of the membrane (seen mainly on day 7 after seeding). By contrast, on membranes with collagen, the cells adhered only on the surface of the protein nanocoating or on the surface of the membrane (Figure 7).

The morphology of the keratinocytes also varied among the different types of samples. On membranes coated with collagen, the cells were well spread and formed larger cell

Table I Variables $\sigma_{t}$ and $u_{z}$ at the mean maximum

\begin{tabular}{llllll}
\hline & PLGA + F & PLGA + C & PLGA & PLA + F & PLA + C \\
\hline$\overline{\sigma_{t}(U S)} \mathrm{MPa}$ & $0.116 \pm 0.032$ & $0.102 \pm 0.04$ & $0.101 \pm 0.036$ & $0.2 \pm 0.086$ & $0.118 \pm 0.039$ \\
$\overline{u_{z}(U S)}(\mathrm{mm})$ & $3.24 \pm 0.49$ & $3.29 \pm 0.22$ & $3.48 \pm 0.33$ & $3.5 \pm 0.45$ & $2.87 \pm 0.61$ \\
\hline
\end{tabular}

Note: Values stated as mean maximum \pm standard deviation.

Abbreviations: PLGA, poly(lactide-co-glycolic acid); PLA, polylactic acid; F, fibrin; C, collagen. 


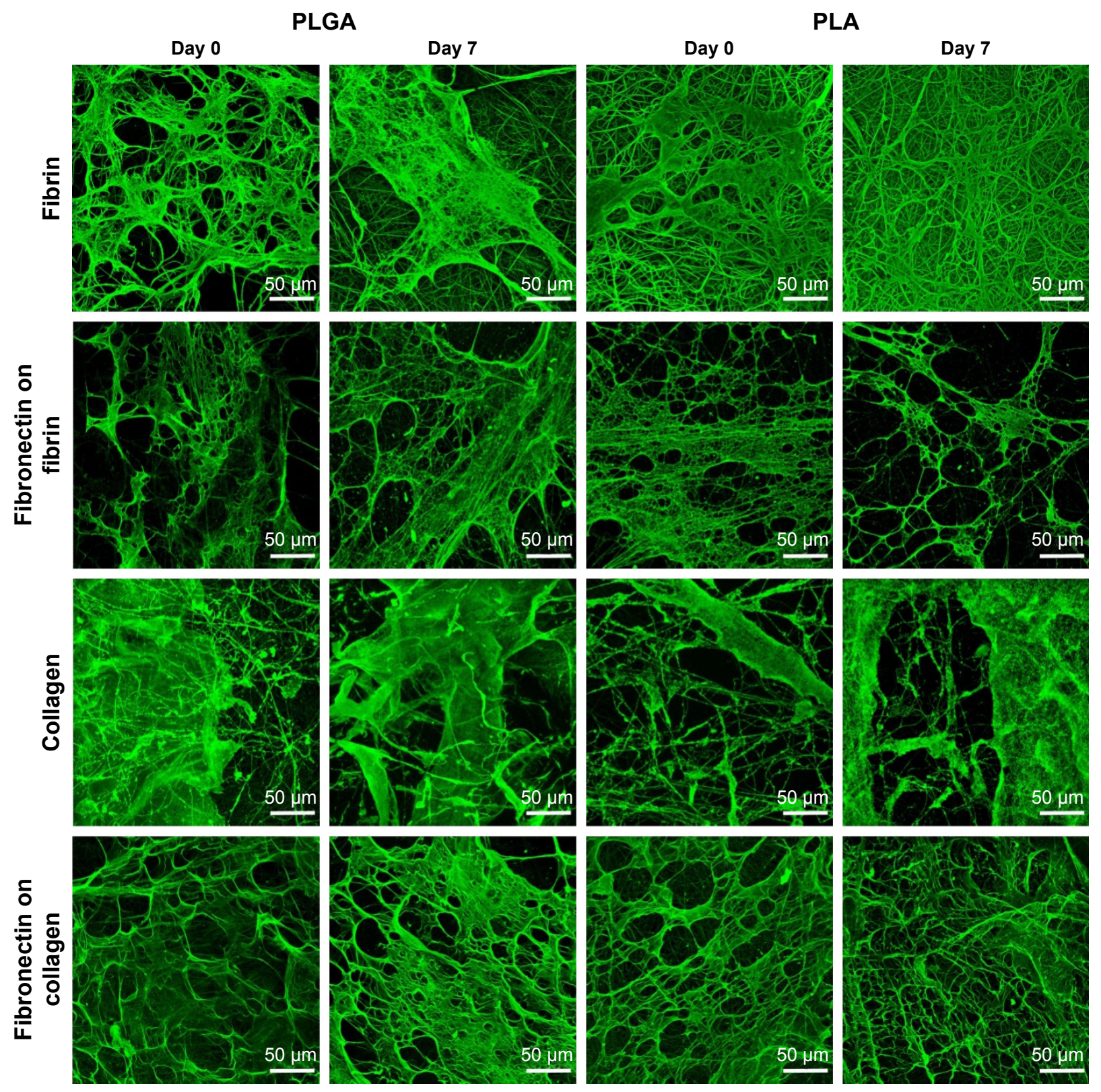

Figure 5 Immunofluorescence staining of protein nanocoating on membrane.

Notes: Fibrin (row I), fibronectin deposited on fibrin (row 2), collagen I (row 3), and fibronectin deposited on collagen (row 4), freshly prepared on PLGA and PLA membranes (day 0) or after 7 days of incubation in DMEM at $37^{\circ} \mathrm{C}$ and $5 \% \mathrm{CO}_{2}$ (day 7). Leica TCS SPE DM2500 confocal microscope, magnification 40×/I.15 NA oil. Abbreviations: PLGA, poly(lactide-co-glycolic acid); PLA, polylactic acid; DMEM, Dulbecco's Modified Eagle’s Medium.

clusters (islands) than on membranes coated with fibrin or on uncoated membranes (Figures 7 and 9). The size of the cell cluster spreading area on day 1 was larger on membranes with collagen than on uncoated membranes or on membranes with fibrin. Fibronectin improved cell attachment on the protein nanocoatings, mainly on the collagen nanocoating, where the largest cell cluster area was observed. The cluster area of keratinocytes on the fibrin nanocoating was only slightly and insignificantly larger than on the uncoated membranes (Figure 10).

\section{Cell proliferation and viability}

Cell proliferation was estimated by measuring cell mitochondrial activity. At all culture time points, the mitochondrial activity of dermal fibroblasts was significantly higher on protein-coated membranes (with the exception of the collagen-coated membranes) than on uncoated (pristine) membranes (Figure 11). On membranes with collagen nanocoating, cell mitochondrial activity was mostly comparable with the metabolic activity of the cells growing on uncoated membranes (with the exception of PLA membranes on day 7 

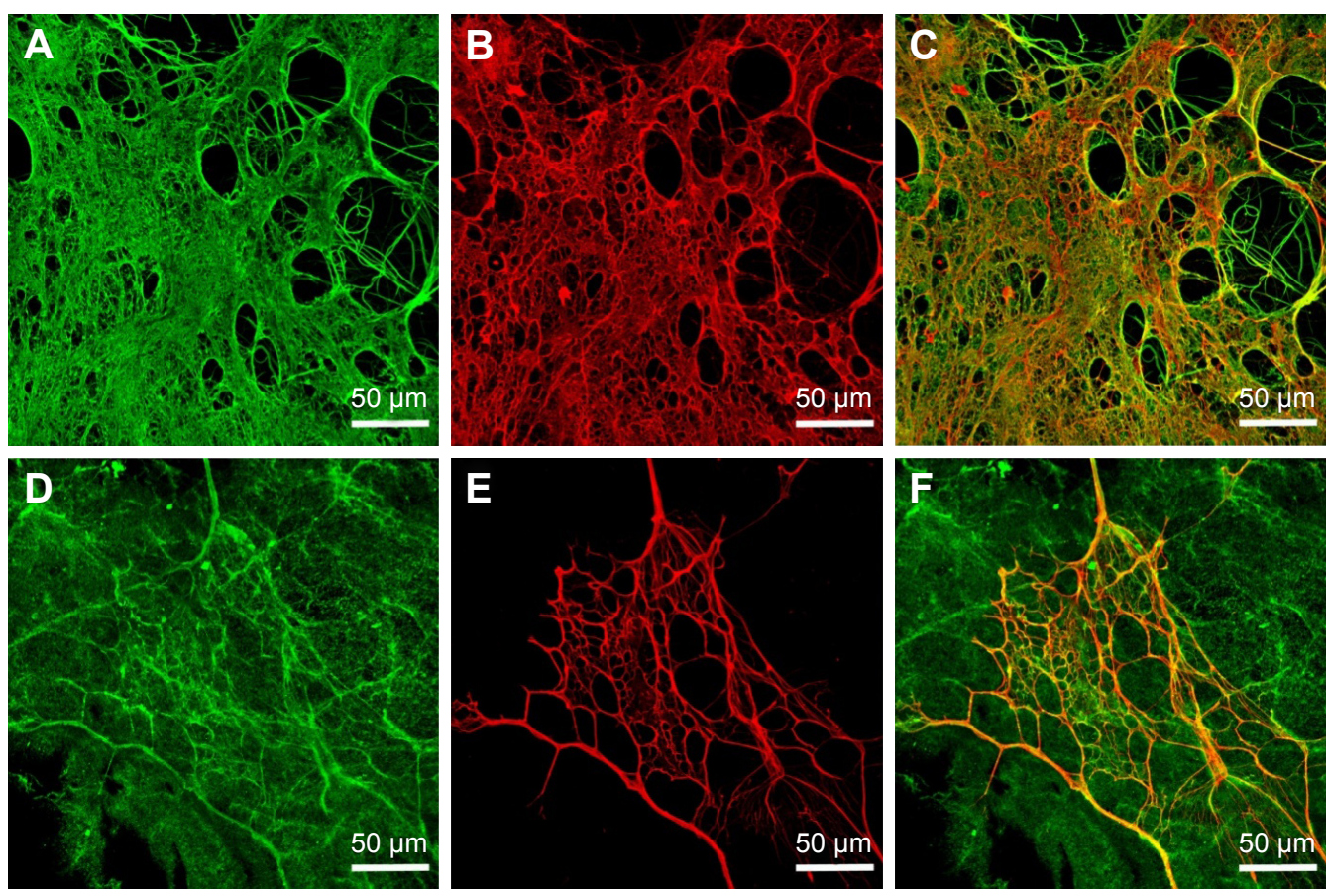

Figure 6 Immunofluorescence staining of protein nanocoating on membrane.

Notes: Fibrin nanocoating (A), collagen nanocoating (D), fibronectin on fibrin nanocoating (B), fibronectin on collagen nanocoating (E), freshly deposited on poly(lactideco-glycolic acid) membranes. Image A was merged with B (C), and image D with E (F). Secondary antibodies were conjugated with Alexa 488 (fibrin, collagen, green fluorescence) or with Alexa 633 (fibronectin, red fluorescence). Leica TCS SPE DM2500 confocal microscope, magnification 40×/I.I5 NA oil.

after cell seeding, where mitochondrial activity was higher). Fibronectin attached to the collagen nanocoating greatly improved fibroblast proliferation. Cell mitochondrial activity on samples of this type was significantly higher than on membranes coated only with collagen. The highest metabolic activity of fibroblasts was found on membranes with fibrin nanocoating. Fibronectin attached to the fibrin nanocoating promoted the attachment of fibroblasts, and further increased their mitochondrial activity. This was apparent mainly on day 3 after seeding.

In comparison with dermal fibroblasts, HaCaT keratinocytes adhered and proliferated better on membranes with a collagen nanocoating than on membranes with a fibrin nanocoating (Figure 12). Cell mitochondrial activity was significantly higher on membranes coated with collagen than on non-coated membranes and on membranes coated with fibrin. Cell mitochondrial activity on fibrin was mostly comparable with activity on uncoated membranes. On fibrin-coated PLGA membranes further modified with fibronectin, cell mitochondrial activity was even lower than on pristine PLGA membranes (Figure 12A). In general, however, there were no major differences in cell adhesion, in mitochondrial activity, or in proliferation between the two types of polymeric membranes, ie, PLGA and PLA membranes (Figures 11 and 12). The viability of both cell types - dermal fibroblasts and $\mathrm{HaCaT}$ keratinocytes - was high and reached almost $100 \%$ on both coated and uncoated membranes. The lower adhesion and proliferation rate of the cells on uncoated membranes did not affect cell viability (Figure 13).

\section{Discussion}

Nanofibrous membranes made from bioresorbable polymers are promising carriers of skin cells for treating acute or chronic wounds. However, the synthetic polymers used for fabricating nanofibrous cell carriers often do not provide sufficient support for cell adhesion, proliferation, or deposition of ECM. Desirable cell behavior can be achieved by modifying the polymer carrier physically or chemically. In our previous studies, modification of PLA membranes by plasma treatment enhanced the adhesion and growth of human keratinocytes, ${ }^{8}$ and fibrin nanocoating on PLA membranes improved the adhesion and proliferation of human fibroblasts, and also collagen synthesis and deposition by these cells as ECM. ${ }^{9}$ Modifying nanofibrous carriers of skin cells by biomolecules naturally occurring in the skin or during skin regeneration could thus be promising for the development of desirable skin substitutes. In this study, we focused on fabricating fibrin, collagen, and fibronectin nanocoatings on nanofibrous PLGA and PLA membranes in order to enhance adhesion, proliferation, and ECM synthesis in skin cells. 

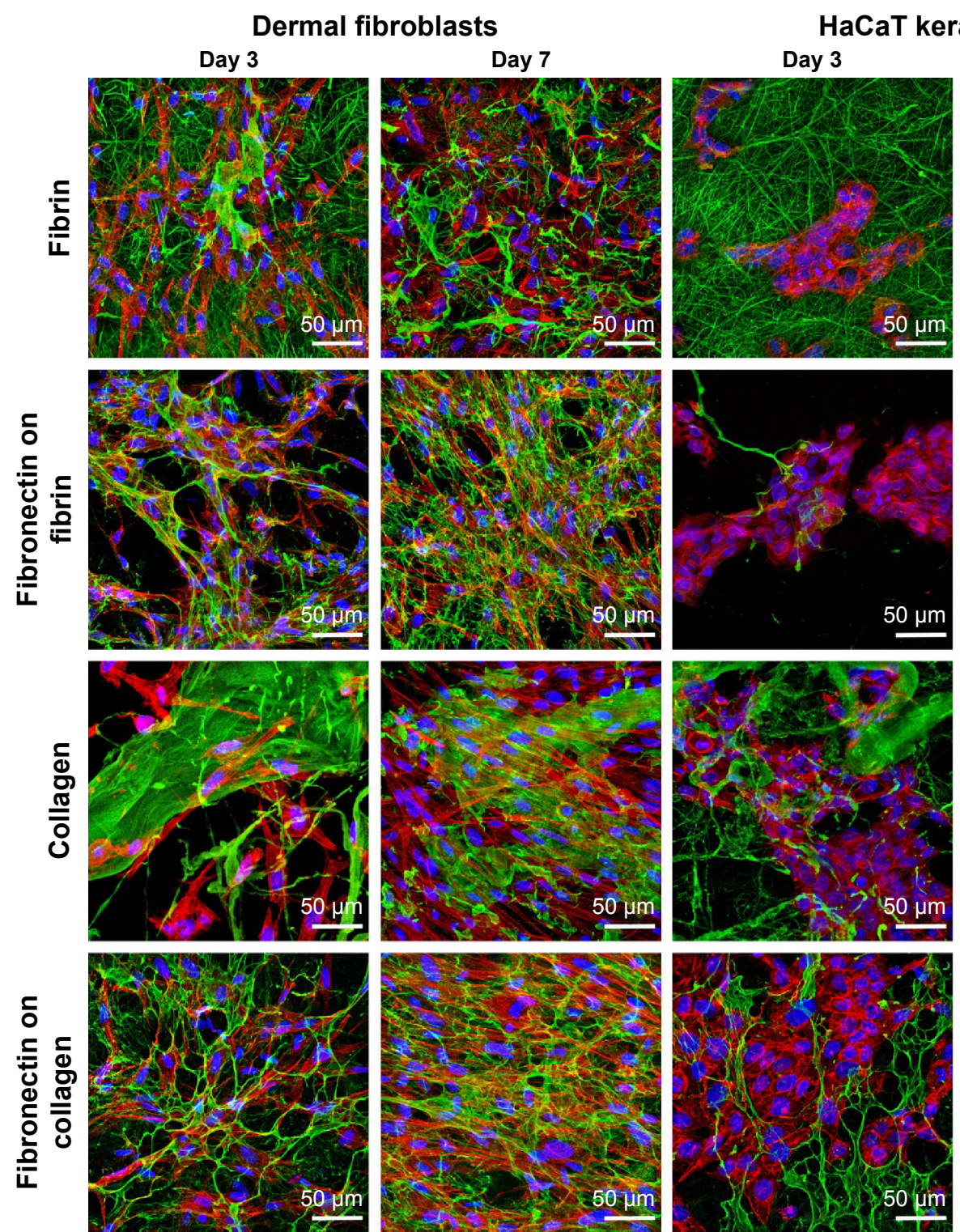

ratinocytes
Day 7
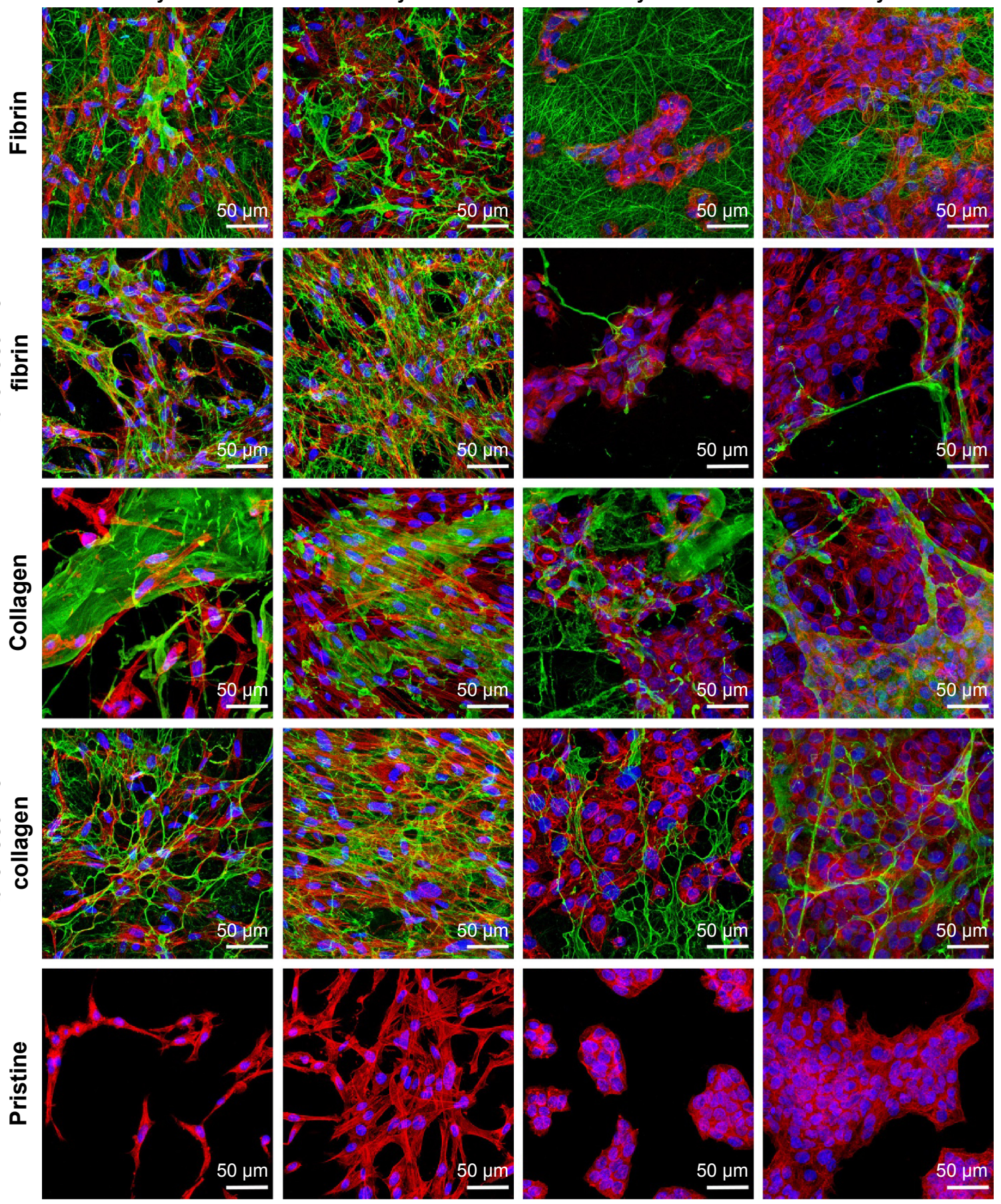

Figure 7 Human dermal fibroblasts and $\mathrm{HaCaT}$ keratinocytes on protein-coated membranes.

Notes: Fibrin (row I), fibronectin deposited on fibrin (row 2), collagen I (row 3), and fibronectin deposited on collagen (row 4) on poly(lactide-co-glycolic acid) membranes after 3 and 7 days of cultivation of human dermal fibroblasts and $\mathrm{HaCaT}$ keratinocytes. Row 5: control cells on pristine uncoated membranes. The protein nanocoating was immunofluorescence stained (green) with primary and secondary antibody conjugated with Alexa 488. The cells were stained with phalloidin-tetramethylrhodamine isothiocyanate (red; actin cytoskeleton) and with Hoechst 33258 (blue; cell nuclei). Leica TCS SPE DM2500 confocal microscope, magnification 40x/I.15 NA oil.

Fibrin deposited on membrane nanofibers greatly improved the adhesion, spreading, and proliferation of dermal fibroblasts. In some places on the membranes, moreover, fibrin formed a thin nanofibrous mesh, mimicking ECM and promoting more cell adhesion and spreading than was observed on unmodified membranes. These results were similar to those obtained in our previous work. As we discussed there, fibrin enabled the cell adhesion receptors to bind to its molecule, and further supported cell adhesion by attracting cell adhesion-mediating molecules (such as 

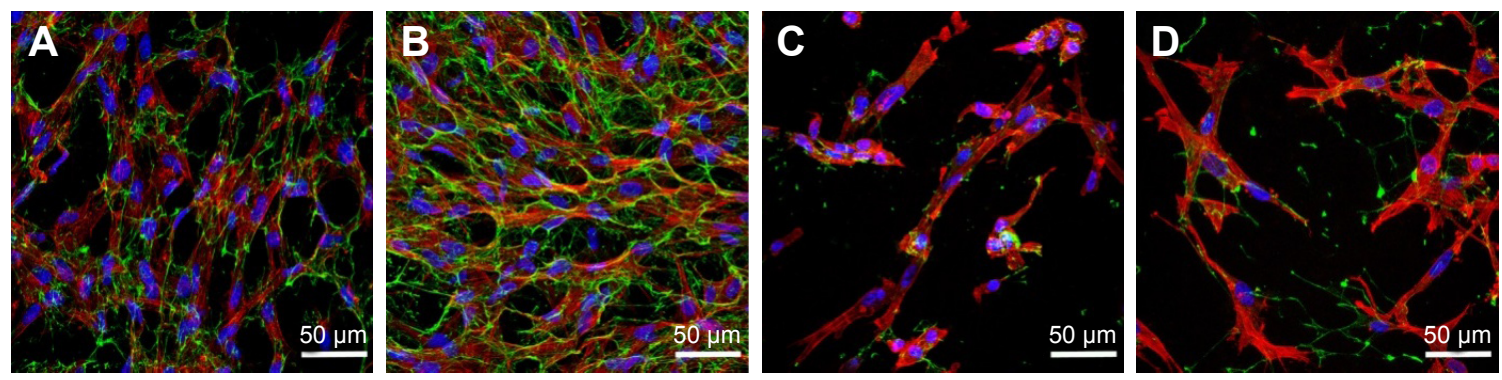

Figure 8 Immunofluorescence staining of fibronectin produced by dermal fibroblasts.

Notes: Fibronectin (green) produced by dermal fibroblasts on poly(lactide-co-glycolic acid) (PLGA) membranes with a fibrin nanocoating (A, B) or on uncoated PLGA membranes (C, D) on day $3(\mathbf{A}, \mathbf{C})$ and on day 7 (B, D) after seeding. Cells were stained with phalloidin-tetramethylrhodamine isothiocyanate (red; actin cytoskeleton) and with Hoechst 33258 (blue; cell nuclei). Leica TCS SPE DM2500 confocal microscope, magnification 40×/I.I5 NA oil.

fibronectin or vitronectin) from the serum supplement of the cell culture medium. We showed that fibrin enhanced the development of focal adhesion plaques containing $\beta_{1}$-integrins in dermal fibroblasts. ${ }^{9}$ Studies by other authors have also shown similar positive effects of fibrin on the adhesion and growth of fibroblasts. ${ }^{41,42}$

However, our results showed that (unlike in the case of fibroblasts) there was not significantly greater proliferation of keratinocytes on fibrin-coated membranes than on uncoated membranes. The explanation for this could be that keratinocytes, unlike fibroblasts, do not naturally come into direct contact with fibrin. During wound healing, fibroblasts migrate into the fibrin clot, start to produce ECM, and are the first to contribute to wound healing. Keratinocytes then migrate to the wound, attach to the ECM matrix, and form new cell layers of epidermis. Many previous studies have attempted to reveal the role of fibrin in the adhesion and proliferation of keratinocytes, but they have not reached consistent conclusions. Sese et al reported that keratinocyte proliferation in three-dimensional fibrin constructs was influenced by thrombin concentration. These authors found that the optimal thrombin concentration in fibrin matrices for stimulating keratinocyte proliferation was about $1 \mathrm{U} / \mathrm{mL},{ }^{43}$ while the proliferation of fibroblasts was not strongly dependent
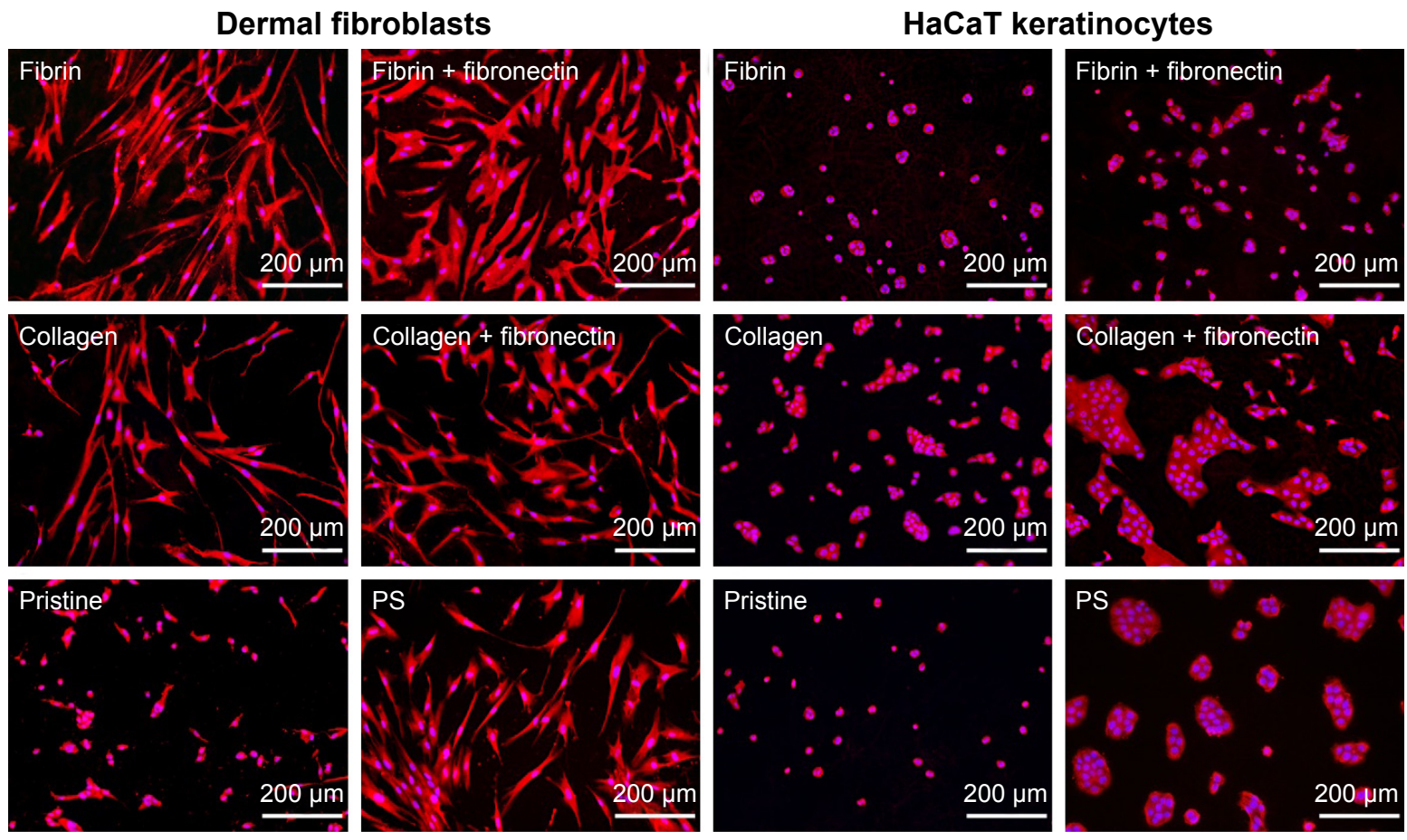

Figure 9 Morphology of human dermal fibroblasts and human $\mathrm{HaCaT}$ keratinocytes.

Notes: Day I after seeding on poly(lactide-co-glycolic acid) (PLGA) membranes coated with fibrin, fibrin + fibronectin, collagen, or collagen + fibronectin, and on uncoated PLGA membranes (pristine). Polystyrene (PS) culture dishes were used as reference material. Cells stained with Texas red $\mathrm{C}_{2}$-maleimide and Hoechst 33258 . Olympus IX 5 I microscope, magnification 10×, DP 70 digital camera. 


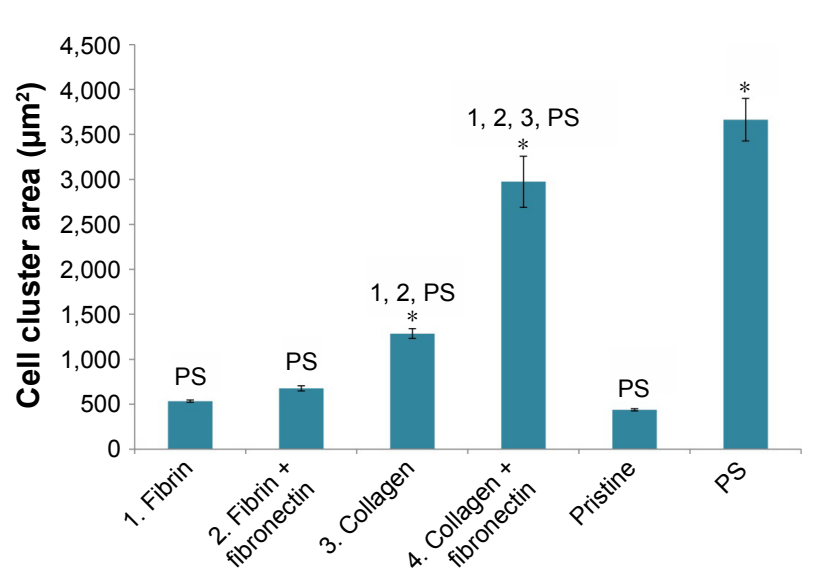

Figure 10 Cell cluster spreading area of $\mathrm{HaCaT}$ keratinocytes.

Notes: Day I after seeding on poly(lactide-co-glycolic acid) membranes in modified states (I-4) or in an unmodified state (pristine). Polystyrene (PS) culture dishes were used as reference material. Arithmetic mean \pm standard error of mean from 283-779 measurements. Analysis of variance, Student-Newman-Keuls method, statistical significance $P \leq 0.05$. I-4, PS in comparison with experimental group of same label; *compared to pristine sample.

on thrombin concentration. Fibroblasts proliferated well within three-dimensional fibrin clots containing 1-167 U/mL of thrombin. ${ }^{44}$ In our study, we used thrombin in a concentration of $2.5 \mathrm{U} / \mathrm{mL}$ to fabricate a fibrin nanocoating. This concentration was optimal for forming the nanocoating on the membrane and for supporting the proliferation of fibroblasts, but it was probably not convenient for the growth of keratinocytes. Gugerell et al reported that high concentrations (about $820 \mathrm{U} / \mathrm{mL}$ ) of thrombin activated apoptotic mechanisms in keratinocytes, and also decreased their attachment and spreading on fibrin sealants. ${ }^{45}$ Kubo et al showed that fibrin and fibrinogen were nonadhesive for keratinocytes, due to a lack in these cells of $\alpha_{\mathrm{v}} \beta_{3}$ integrin receptors, which are important for binding cells to fibrin molecules ${ }^{46}$ In our study, the HaCaT keratinocytes were able to adhere to fibrin-coated membranes, though they were not so well flattened as on collagen-coated membranes. This may be explained by the relatively long exposure of the fibrin coatings to the adhering keratinocytes, ie, more than 24 hours, which is sufficient time for these cells to alter or to remove the protein coating in order to enhance their adhesion. ${ }^{46}$ In addition, the adhesion and proliferation of keratinocytes on fibrin matrices can be improved by cross-linking them, eg, by factor XII, and also by adding fibronectin. ${ }^{47}$ It cannot be excluded that fibronectin, which is present in the serum supplement of the culture medium, was bound onto our fibrin matrices through their $\alpha \mathrm{C}$ domains, ${ }^{22}$ and was then recognized by the $\alpha_{5} \beta_{1}, \alpha_{v} \beta_{1}$, and $\alpha_{v} \beta_{6}$ integrin-adhesion receptors present on keratinocytes, including $\mathrm{HaCaT}^{48}$ However, in our study, the attachment of fibronectin to fibrin coatings did not significantly improve the adhesion or growth of keratinocytes, although this cell behavior was expected.

Our experiments also suggested that fibrin stimulated fibroblasts to synthesize fibronectin and deposit it as ECM in the cell surroundings. On the fibrin coating, the amount of fibronectin in the cell surroundings increased markedly from day 3 to day 7 , and the fibronectin was clearly associated with the cells, ie, it was localized in the immediate vicinity of the cell membrane. This was particularly apparent on day 7 , when fibronectin clearly contoured the cells (Figure 8). This pattern could be attributed to de novo synthesis of fibronectin by the cells, rather than to its spontaneous adsorption or binding
A

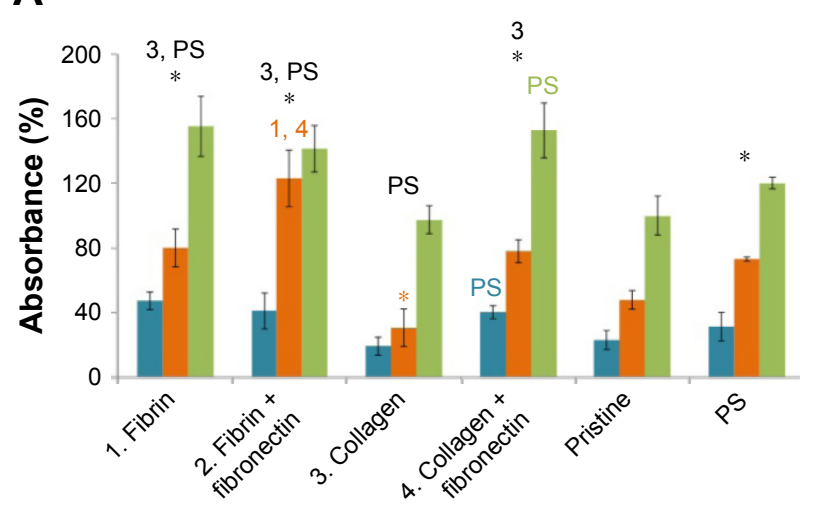

B

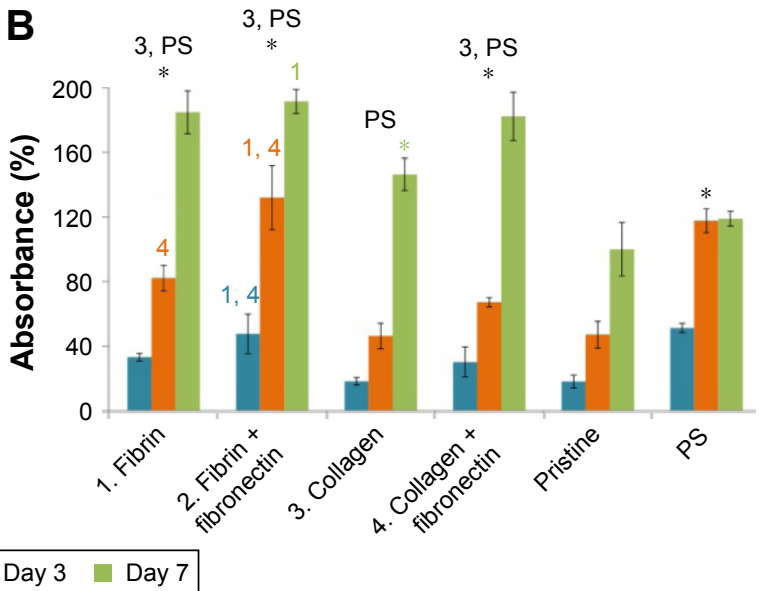

Figure I I Mitochondrial activity in human dermal fibroblasts determined by MTS assay at three time points (on days I, 3, and 7 after cell seeding).

Notes: On a poly(lactide-co-glycolic acid) membrane (A) or polylactic acid membrane (B) in modified states (I-4) or in an unmodified state (pristine). Polystyrene (PS) culture dishes were used as reference material. Arithmetic mean \pm standard deviation values from 12 measurements made on three independent samples for each experimental group and time point. Analysis of variance, Student-Newman-Keuls method, statistical significance $P \leq 0.05$. I-4, PS in comparison with experimental group of same label; *compared to pristine sample at all three time points (black label) or at particular points (color label). 

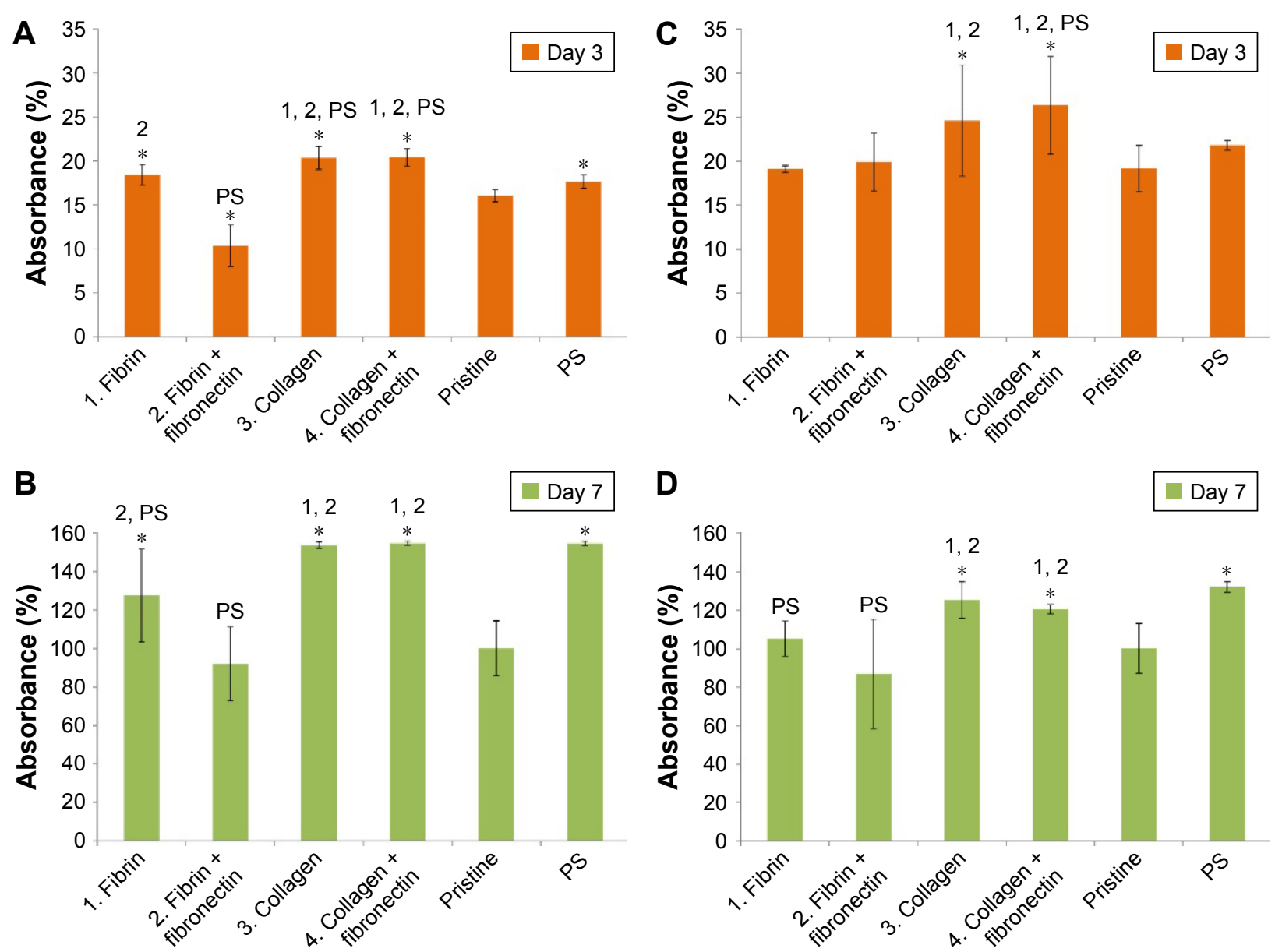

Figure 12 Mitochondrial activity in human HaCaT keratinocytes determined by MTS assay at two time points (on days 3 and 7 after cell seeding).

Notes: On poly(lactide-co-glycolic acid) (A, B) or polylactic acid membranes (C, D) in modified states (I-4) or in an unmodified state (pristine). Polystyrene (PS) culture dishes were used as control material. Arithmetic mean \pm standard deviation values from 12 measurements made on three independent samples for each experimental group and time point. Analysis of variance, Student-Newman-Keuls method, statistical significance $P \leq 0.05$. I -4 , PS in comparison with experimental group of same label; *compared to pristine sample.

to fibrin from the serum of the culture medium. A similar pattern of fibronectin deposition was observed in cardiac fibroblasts cultured on three-dimensional fibrin gels. ${ }^{49}$ In our previous study, we showed that fibroblasts were stimulated by a fibrin nanocoating to produce collagen ECM fibers. ${ }^{9}$ Studies by other authors have also described a stimulatory effect of fibrin on ECM synthesis (mainly collagen I) by fibroblasts. ${ }^{42,50}$

Collagen deposited on the membranes also enhanced adhesion, spreading, and proliferation of the cells, particularly of HaCaT keratinocytes. Collagen is a major component of ECM, and most of the cells bind to its oligopeptide sequence DGEA (Asp-Gly-Glu-Ala), mainly by $\alpha_{2} \beta_{1}$ or $\alpha_{3} \beta_{1}$ integrin receptors. ${ }^{51,52}$ These receptors are also expressed in $\mathrm{HaCaT}$ keratinocytes. ${ }^{53}$ The HaCaT keratinocytes in our study adhered, spread, and proliferated faster on collagen-coated membranes than on fibrin-coated or uncoated membranes.
After skin injury, keratinocytes physiologically migrate into the wound and interact through their integrin receptors with ECM molecules, mainly with collagen I nanofibers. ${ }^{11}$ It seems to be beneficial to modify nanofibrous scaffolds by collagen or directly to fabricate collagen nanofibrous scaffolds..$^{38,40}$ The native ECM in the dermis consists of collagen nanofibers less than $100 \mathrm{~nm}$ in diameter. However, the diameter of collagen fibers in nanofibrous matrices is usually greater than $100 \mathrm{~nm} \cdot{ }^{39}$ For this reason, Fu et al developed composite polycaprolactone-collagen nanofibrous matrices coated with a thin layer of collagen gel, forming a secondary ultrafine network of nanofibers ( $55 \pm 26 \mathrm{~nm}$ in diameter), in order to simulate natural conditions better. This ultrafine collagen fibrous network significantly increased the adhesion and migration of keratinocytes in comparison with unmodified polycaprolactone-collagen composite fibers, which were $331 \pm 112 \mathrm{~nm}$ in diameter. ${ }^{39}$ Therefore, the improvement in the adhesion and growth of keratinocytes on our 


\section{Dermal fibroblasts}
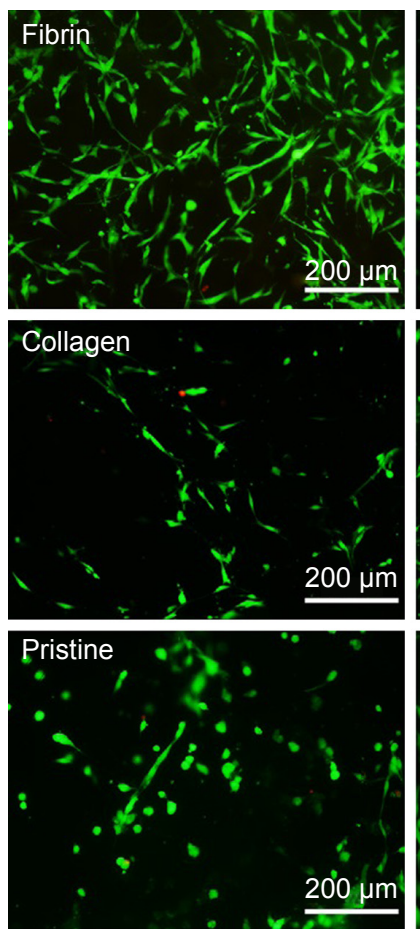
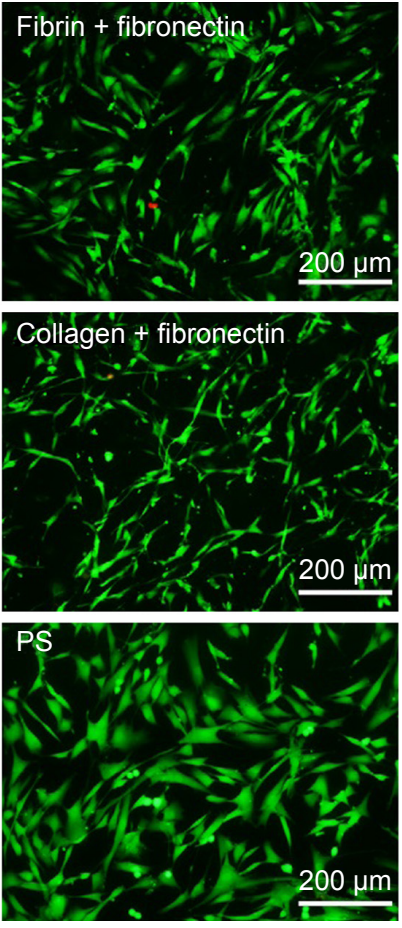

HaCaT keratinocytes
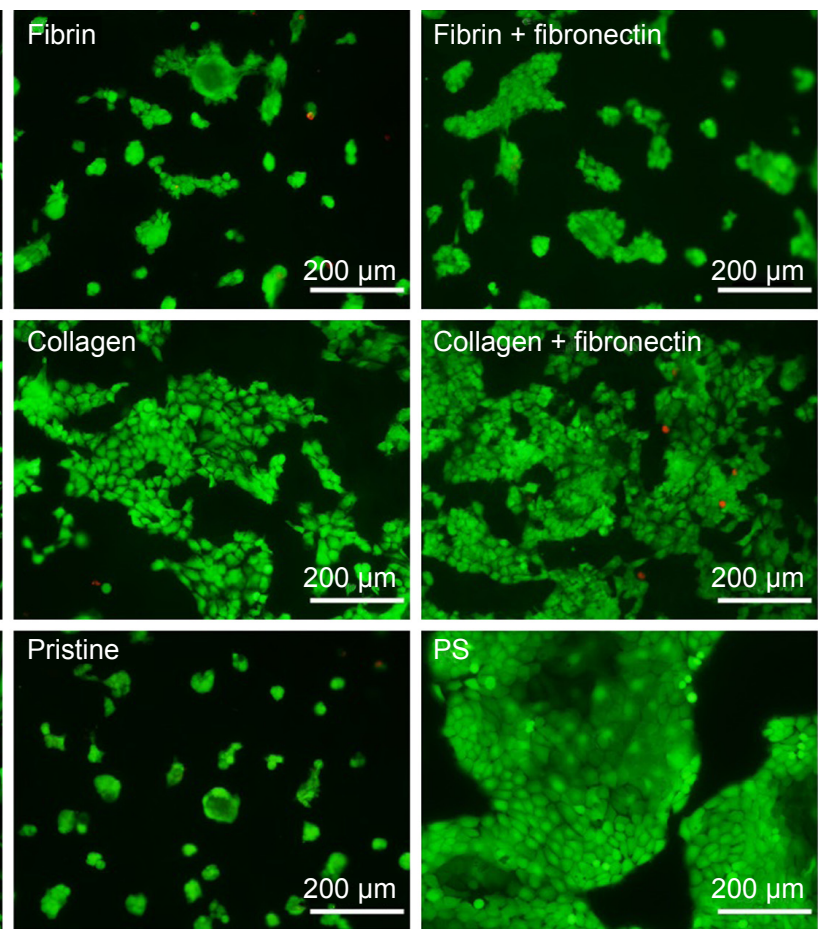

Figure 13 Viability of human dermal fibroblasts and human $\mathrm{HaCaT}$ keratinocytes determined by a live/dead kit.

Notes: Day I after seeding on poly(lactide-co-glycolic acid) (PLGA) membranes coated with fibrin, fibrin + fibronectin, collagen, or collagen + fibronectin, and on uncoated PLGA membranes (pristine). Polystyrene (PS) culture dishes used as reference material. Cells stained with calcein AM (green, live cells) and with ethidium homodimer I (red, dead cells). Olympus IX 5 I microscope, magnification I0X, DP 70 digital camera.

collagen-modified PLA and PLGA nanofibrous membranes can be explained by the formation of a soft collagen gel on the membrane surface, rather than to the collagen coating of the individual fibers in the membranes.

In contrast to keratinocytes, the adhesion and proliferation of dermal fibroblasts on collagen-coated membranes was usually similar to the adhesion and proliferation on uncoated membranes. Dermal fibroblasts naturally generate contractile forces that affect the surrounding tissue. During wound healing, the fibroblasts produce strong ECM fibers made of collagen and elastin, which resist the traction forces of the cells. Similarly, when cells are seeded on a biomaterial support in vitro, the cells subject this support to traction forces generated by the actin cytoskeleton during cell adhesion, spreading, and migration. ${ }^{4,54}$ However, on our membranes, the collagen mostly formed a gel that was probably too soft and was deformed by the traction forces generated by the fibroblasts. In addition, the collagen coating did not improve mechanical properties compared to the fibrin coating, which showed an increase in membrane stiffness. Therefore, the fibrin coating was able to resist contractile forces from fibroblasts better than the collagen gel. The collagen gel was thus probably not able to provide an appropriate substrate for the attachment and migration of dermal fibroblasts. This was suggested by the fibroblast peeling of the collagen gel observed in our study.

Eastwood et al made a systematic study of the generation of contractile forces by dermal fibroblasts on a collagen gel. They found that most of the forces were induced during attachment and spreading of the cells, and different groups of fibroblasts might vary in their contraction activity. ${ }^{55}$ The different behavior of the fibroblasts and the keratinocytes on our collagen-coated membranes was probably due to the different contraction forces generated by these cells on the collagen gel. Agis et al compared fibroblast behavior on a collagen gel and on a collagen porous sponge. They found that the collagen sponge provided better support for cell migration, proliferation, and ECM production than the collagen gel..$^{56}$ These results suggest that for the fibroblast component of a skin substitute, it would be better to use nanofibrous scaffolds made of pure collagen, or collagen combined with other degradable materials, as mentioned earlier. ${ }^{38,40}$ Mateos-Timoneda et al fabricated polylactide films and fibers covalently bond with collagen. In contrast to our results, they observed significant positive effects on adhesion and proliferation of dermal fibroblasts. The covalently 
bond collagen probably was able to better resist contractile forces of fibroblasts, and provide them with a more stable substrate for adhesion. ${ }^{57}$

Fibronectin was deposited on a fibrin or collagen nanocoating in order to enhance the attachment and spreading of the cells. Fibronectin is the main adhesive protein of the ECM and is bound by cell integrin-adhesion receptors through the RGD amino acid sequence (Arg-Gly-Asp).$^{58}$ Fibronectin attached to collagen-coated membranes improved the adhesion and spreading of HaCaT keratinocytes. The measured cell cluster area, ie, the size of the keratinocyte islands formed on day 1 after seeding, was larger on fibronectincollagen-coated membranes than on collagen-only-coated membranes. Moreover, fibronectin attached to a collagen and fibrin nanocoating enhanced the proliferation of dermal fibroblasts. This positive effect was more pronounced on collagen-coated membranes, ie, on a material where the adhesion and growth of fibroblasts were less stimulated than on fibrin. The enhancement of fibroblast proliferation by fibronectin was probably due to better primary attachment of the cells.

The way in which the cells degraded and reorganized the protein nanocoatings differed between fibroblasts and keratinocytes. The fibroblasts slowly and continuously degraded and reorganized all types of protein nanocoatings during cultivation, whereas the effects of HaCaT keratinocytes were different on fibrin-based nanocoatings and on collagen-based nanocoatings. The morphology of the collagen nanocoating was not significantly changed by the keratinocyte behavior. However, the morphology of the thin fibrous mesh of a fibrin nanocoating was strongly altered by keratinocytes already 24 hours after cell seeding. Interestingly, while fibronectin attached to fibrin was significantly degraded by keratinocytes, fibronectin attached to collagen was not significantly degraded. During the attachment, spreading, and migration of keratinocytes, the cells develop traction forces that affect the ECM. The thin fibrous fibrin mesh was probably not able to resist these contractile forces, and was pulled down at an early stage, together with the attached fibronectin. However, the collagen coating probably provided a firmer surface for keratinocyte adhesion and migration. In addition, the collagen gel that formed on the surface of the nanofibrous membranes provided a relatively flat growth support, which may be more convenient for the adhesion of keratinocytes, ie, flat and polygonal epithelial cells. Last but not least, keratinocytes lack $\alpha_{v} \beta_{3}$ integrin receptors, which are important for binding to fibrin molecules. They thus did not use the fibrin molecules as a substrate for their adhesion, migration, or growth, and they tried to reorganize or even remove this coating. From physiological wound healing in vivo, it is known that keratinocytes slough the fibrin eschar from the newly formed epidermis. ${ }^{46}$

On the PLA and PLGA membranes, there was no apparent difference in the morphology of the protein nanocoatings nor in the cell behavior on these coatings. Cell behavior was also similar on both types of nanofibrous membranes. Both PLA and PLGA are degradable polyesters widely used in tissue engineering and in other biotechnologies, eg, for drug delivery. However, certain differences have been reported in the behavior of the two polymers in the biological environment. For example, when prepared in the form of microspheres for drug delivery, PLA has a longer degradation time than PLGA, and the degradation time of PLGA decreases with a decreasing percentage of PLA in this copolymer. ${ }^{59}$ Accordingly, the loss of mechanical integrity is faster in PLGA than in PLA. ${ }^{31}$ PLA microspheres show a more porous and hydrophobic surface than PLGA, which results in differences in protein adsorption on these polymers, including fibrinogen. PLA adsorbs slightly more fibronectin, but also more albumin, which is nonadhesive for cells. ${ }^{32}$ The adhesion and proliferation of porcine chondrocytes is better on PLGA films (ratio 85:15) than on PLA films. ${ }^{34}$ Similarly, rat osteoblasts cultured on PLGA films (ratio 75:25) show increased activity of alkaline phosphatase, ie, a marker of osteogenic cell differentiation, than cells on PLA films. ${ }^{33}$ In serum free-medium, pristine PLA and PLGA, in forms of both films and fibers, strongly reduce the adhesion of human dermal fibroblasts in comparison with tissue-culture polystyrene, and this adhesion is markedly improved when the polymer materials are covalently bound with collagen I. ${ }^{57}$

\section{Conclusion and future perspectives}

The protein nanocoatings developed in our study on nanofibrous PLGA and PLA membranes had a major influence on the behavior of skin cells. The behavior of the cells was different on fibrin than on collagen nanocoating. Fibrin enhanced the adhesion, spreading, proliferation, and fibronectin ECM synthesis of human dermal fibroblasts. In contrast to fibroblasts, $\mathrm{HaCaT}$ keratinocytes adhered, spread, and proliferated more quickly on collagen-coated membranes than on fibrin-coated or uncoated membranes. Fibronectin attached to fibrin or to a collagen nanocoating further enhanced cell adhesion and spreading. Moreover, fibronectin increased fibroblast proliferation. No differences were observed in the adhesion or growth of the cells on PLGA and PLA membranes. 
Taken together, a degradable nanofibrous membrane with protein nanocoating could be promising for the construction of a bilayered skin substitute. On one side of the membrane, the fibrin-coated nanofibers could support the adhesion, proliferation, and ECM synthesis of fibroblasts. With its collagen nanocoating, the opposite side of the membrane could serve as an appropriate carrier for keratinocytes.

\section{Acknowledgments}

This study was supported by the Grant Agency of Charles University in Prague (grant 38214) and by the Grant Agency of the Czech Republic (grant P108/12/G108). Mr Robin Healey (Czech Technical University in Prague) is gratefully acknowledged for his language revision of the manuscript.

\section{Disclosure}

The authors report no conflicts of interest in this work.

\section{References}

1. Eisenbud D, Huang NF, Luke S, Silberklang M. Skin substitutes and wound healing: current status and challenges. Wounds. 2004; 16(1):2-17.

2. McMillan JR, Akiyama M, Tanaka M, et al. Small-diameter porous poly( $\varepsilon$-caprolactone) films enhance adhesion and growth of human cultured epidermal keratinocyte and dermal fibroblast cells. Tissue Eng. 2007;13(4):789-798.

3. Sun L, Stout DA, Webster TJ. The nano-effect: improving the longterm prognosis for musculoskeletal implants. J Long Term Eff Med Implants. 2012;22(3):195-209.

4. Bacakova L, Filova E, Parizek M, Ruml T, Svorcik V. Modulation of cell adhesion, proliferation and differentiation on materials designed for body implants. Biotechnol Adv. 2011;29(6):739-767.

5. Groeber F, Holeiter M, Hampel M, Hinderer S, Schenke-Layland K. Skin tissue engineering: in vivo and in vitro applications. Adv Drug Deliv Rev. 2011;63(4-5):352-366.

6. Kai D, Liow SS, Loh XJ. Biodegradable polymers for electrospinning: towards biomedical applications. Mater Sci Eng C Mater Biol Appl. 2014;45:659-670.

7. Hoveizi E, Nabiuni M, Parivar K, Rajabi-Zeleti S, Tavakol S. Functionalisation and surface modification of electrospun polylactic acid scaffold for tissue engineering. Cell Biol Int. 2014;38(1): 41-49.

8. Bacakova M, Lopot F, Hadraba D, et al. Effects of fiber density and plasma modification of nanofibrous membranes on the adhesion and growth of HaCaT keratinocytes. J Biomater Appl. 2015;29(6): 837-853.

9. Bacakova M, Musilkova J, Riedel T, et al. The potential applications of fibrin-coated electrospun polylactide nanofibers in skin tissue engineering. Int J Nanomedicine. 2016;11:771-789.

10. Rajangam T, An SS. Fibrinogen and fibrin based micro and nano scaffolds incorporated with drugs, proteins, cells and genes for therapeutic biomedical applications. Int J Nanomedicine. 2013;8:3641-3662.

11. O'Toole EA. Extracellular matrix and keratinocyte migration. Clin Exp Dermatol. 2001;26(6):525-530.

12. Auxenfans C, Fradette J, Lequeux C, et al. Evolution of three dimensional skin equivalent models reconstructed in vitro by tissue engineering. Eur J Dermatol. 2009;19(2):107-113.

13. Nuutila K, Peura M, Suomela S, et al. Recombinant human collagen III gel for transplantation of autologous skin cells in porcine full-thickness wounds. J Tissue Eng Regen Med. 2015;9(12):1386-1393.
14. Sarkar SD, Farrugia BL, Dargaville TR, Dhara S. Chitosan-collagen scaffolds with nano/microfibrous architecture for skin tissue engineering. J Biomed Mater Res A. 2013;101(12):3482-3492.

15. Peh P, Lim NS, Blocki A, et al. Simultaneous delivery of highly diverse bioactive compounds from blend electrospun fibers for skin wound healing. Bioconjug Chem. 2015;26(7):1348-1358.

16. Niiyama H, Kuroyanagi Y. Development of novel wound dressing composed of hyaluronic acid and collagen sponge containing epidermal growth factor and vitamin C derivative. J Artif Organs. 2014;17(1): 81-87.

17. Butler CE, Orgill DP. Simultaneous in vivo regeneration of neodermis, epidermis, and basement membrane. Adv Biochem Eng Biotechnol. 2005;94:23-41.

18. Wang F, Wang M, She Z, et al. Collagen/chitosan based twocompartment and bi-functional dermal scaffolds for skin regeneration. Mater Sci Eng C Mater Biol Appl. 2015;52:155-162.

19. Anish S. Skin substitutes in dermatology. Indian J Dermatol Venereol Leprol. 2015;81(2):175-178.

20. Debels H, Hamdi M, Abberton K, Morrison W. Dermal matrices and bioengineered skin substitutes: a critical review of current options. Plast Reconstr Surg Glob Open. 2015;3(1):e284.

21. Mutsaers SE, Bishop JE, McGrouther G, Laurent GJ. Mechanisms of tissue repair: from wound healing to fibrosis. Int J Biochem Cell Biol. 1997;29(1):5-17.

22. Laurens N, Koolwijk P, de Maat MP. Fibrin structure and wound healing. J Thromb Haemost. 2006;4(5):932-939.

23. Gorodetsky R, Clark RA, An J, et al. Fibrin microbeads (FMB) as biodegradable carriers for culturing cells and for accelerating wound healing. J Invest Dermatol. 1999;112(6):866-872.

24. Fabris G, Trombelli L, Schincaglia GP, Cavallini R, Calura G, del Senno L. Effects of a fibrin-fibronectin sealing system on proliferation and type I collagen synthesis of human PDL fibroblasts in vitro. J Clin Periodontol. 1998;25(1):11-14.

25. Ahmed TA, Dare EV, Hincke M. Fibrin: a versatile scaffold for tissue engineering applications. Tissue Eng Part B Rev. 2008;14(2): 199-215.

26. Braziulis E, Biedermann T, Hartmann-Fritsch F, et al. Skingineering I: engineering porcine dermo-epidermal skin analogues for autologous transplantation in a large animal model. Pediatr Surg Int. 2011;27(3): 241-247.

27. Mazzone L, Pontiggia L, Reichmann E, Ochsenbein-Kölble N, Moehrlen U, Meuli M. Experimental tissue engineering of fetal skin. Pediatr Surg Int. 2014;30(12):1241-1247.

28. Monteiro IP, Gabriel D, Timko BP, et al. A two-component pre-seeded dermal-epidermal scaffold. Acta Biomater. 2014;10(12):4928-4938.

29. de la Puente P, Ludena D, Fernandez A, Aranda JL, Varela G, Iglesias J. Autologous fibrin scaffolds cultured dermal fibroblasts and enriched with encapsulated bFGF for tissue engineering. J Biomed Mater Res A. 2011;99(4):648-654.

30. Sivan U, Jayakumar K, Krishnan LK. Constitution of fibrin-based niche for in vitro differentiation of adipose-derived mesenchymal stem cells to keratinocytes. Biores Open Access. 2014;3(6):339-347.

31. Kranz H, Ubrich N, Maincent P, Bodmeier R. Physicomechanical properties of biodegradable poly(D,L-lactide) and poly(D,L-lactide-coglycolide) films in the dry and wet states. J Pharm Sci. 2000;89(12): 1558-1566.

32. Lück M, Pistel KF, Li YX, Blunk T, Müller RH, Kissel T. Plasma protein adsorption on biodegradable microspheres consisting of poly(D,Llactide-co-glycolide), poly(L-lactide) or ABA triblock copolymers containing poly(oxyethylene): influence of production method and polymer composition. J Control Release. 1998;55(2-3):107-120.

33. Ishaug SL, Yaszemski MJ, Bizios R, Mikos AG. Osteoblast function on synthetic biodegradable polymers. J Biomed Mater Res. 1994;28(12): 1445-1453.

34. Tsai WB, Chen CH, Chen JF, Chang KY. The effects of types of degradable polymers on porcine chondrocyte adhesion, proliferation and gene expression. J Mater Sci Mater Med. 2006;17(4):337-343. 
35. Riedel T, Brynda E, Dyr JE, Houska M. Controlled preparation of thin fibrin films immobilized at solid surfaces. J Biomed Mater Res A. 2009;88(2):437-447.

36. Boukamp P, Petrussevska RT, Breitkreutz D, Hornung J, Markham A, Fusenig NE. Normal keratinization in a spontaneously immortalized aneuploid human keratinocyte cell line. J Cell Biol. 1988;106(3): 761-771.

37. Hornig-Do HT, von Kleist-Retzow JC, Lanz K, et al. Human epidermal keratinocytes accumulate superoxide due to low activity of Mn-SOD, leading to mitochondrial functional impairment. J Invest Dermatol. 2007; 127(5):1084-1093.

38. Rho KS, Jeong L, Lee G, et al. Electrospinning of collagen nanofibers: effects on the behavior of normal human keratinocytes and early-stage wound healing. Biomaterials. 2006;27(8):1452-1461.

39. Fu X, Xu M, Liu J, Qi Y, Li S, Wang H. Regulation of migratory activity of human keratinocytes by topography of multiscale collagen-containing nanofibrous matrices. Biomaterials. 2014;35(5):1496-1506.

40. Mahjour SB, Fu X, Yang X, Fong J, Sefat F, Wang H. Rapid creation of skin substitutes from human skin cells and biomimetic nanofibers for acute full-thickness wound repair. Burns. 2015;41(8):1764-1774.

41. Mazlyzam AL, Aminuddin BS, Fuzina NH, et al. Reconstruction of living bilayer human skin equivalent utilizing human fibrin as a scaffold. Burns. 2007;33(3):355-363.

42. Nair RP, Joseph J, Harikrishnan VS, Krishnan VK, Krishnan L. Contribution of fibroblasts to the mechanical stability of in vitro engineered dermal-like tissue through extracellular matrix deposition. Biores Open Access. 2014;3(5):217-225.

43. Sese N, Cole M, Tawil B. Proliferation of human keratinocytes and cocultured human keratinocytes and fibroblasts in three-dimensional fibrin constructs. Tissue Eng Part A. 2011;17(3-4):429-437.

44. Cox S, Cole M, Tawil B. Behavior of human dermal fibroblasts in three-dimensional fibrin clots: dependence on fibrinogen and thrombin concentration. Tissue Eng. 2004;10(5-6):942-954.

45. Gugerell A, Schossleitner K, Wolbank S, et al. High thrombin concentrations in fibrin sealants induce apoptosis in human keratinocytes. J Biomed Mater Res A. 2012;100(5):1239-1247.

46. Kubo M, Van de Water L, Plantefaber LC, et al. Fibrinogen and fibrin are anti-adhesive for keratinocytes: a mechanism for fibrin eschar slough during wound repair. J Invest Dermatol. 2001;117(6):1369-1381.

47. Weiss E, Yamaguchi Y, Falabella A, Crane S, Tokuda Y, Falanga V. Un-cross-linked fibrin substrates inhibit keratinocyte spreading and replication: correction with fibronectin and factor XIII cross-linking. J Cell Physiol. 1998;174(1):58-65.
48. Koivisto L, Larjava K, Häkkinen L, Uitto VJ, Heino J, Larjava H. Different integrins mediate cell spreading, haptotaxis and lateral migration of HaCaT keratinocytes on fibronectin. Cell Adhes Commun. 1999; $7(3): 245-257$.

49. Trombetta-Esilva J, Eadie EP, Zhang Y, Norris RA, Borg TK, Bradshaw AD. The effects of age and the expression of SPARC on extracellular matrix production by cardiac fibroblasts in 3-D cultures. PLoS One. 2013;8(11):e79715.

50. Tuan TL, Song A, Chang S, Younai S, Nimni ME. In vitro fibroplasia: matrix contraction, cell growth, and collagen production of fibroblasts cultured in fibrin gels. Exp Cell Res. 1996;223(1):127-134.

51. Marchisio PC, Cancedda R, De Luca M. Structural and functional studies of integrin receptors in cultured human keratinocytes. Cell Differ Dev. 1990;32(3):355-359.

52. Staatz WD, Fok KF, Zutter MM, Adams SP, Rodriguez BA, Santoro SA. Identification of a tetrapeptide recognition sequence for the $\alpha_{2} \beta_{1}$ integrin in collagen. J Biol Chem. 1991;266(12):7363-7367.

53. Scharffetter-Kochanek K, Klein CE, Heinen G, et al. Migration of a human keratinocyte cell line (HACAT) to interstitial collagen type I is mediated by the $\alpha_{2} \beta_{1}$-integrin receptor. J Invest Dermatol. 1992; 98(1):3-11.

54. Engler A, Bacakova L, Newman C, Hategan A, Griffin M, Discher D. Substrate compliance versus ligand density in cell on gel responses. Biophys J. 2004;86(1 Pt 1):617-628.

55. Eastwood M, Porter R, Khan U, McGrouther G, Brown R. Quantitative analysis of collagen gel contractile forces generated by dermal fibroblasts and the relationship to cell morphology. J Cell Physiol. 1996; 166(1):33-42.

56. Agis H, Collins A, Taut AD, et al. Cell population kinetics of collagen scaffolds in ex vivo oral wound repair. PLoS One. 2014;9(11): e112680.

57. Mateos-Timoneda MA, Castano O, Planell JA, Engel E. Effect of structure, topography and chemistry on fibroblast adhesion and morphology. J Mater Sci Mater Med. 2014;25(7):1781-1787.

58. Ruoslahti E, Pierschbacher MD. New perspectives in cell adhesion: RGD and integrins. Science. 1987;238(4826):491-497.

59. Shive MS, Anderson JM. Biodegradation and biocompatibility of PLA and PLGA microspheres. Adv Drug Deliv Rev. 1997;28(1):5-24.
International Journal of Nanomedicine

\section{Publish your work in this journal}

The International Journal of Nanomedicine is an international, peerreviewed journal focusing on the application of nanotechnology in diagnostics, therapeutics, and drug delivery systems throughout the biomedical field. This journal is indexed on PubMed Central, MedLine, CAS, SciSearch ${ }^{\circledR}$, Current Contents ${ }^{\circledR} /$ Clinical Medicine,

\section{Dovepress}

Journal Citation Reports/Science Edition, EMBase, Scopus and the Elsevier Bibliographic databases. The manuscript management system is completely online and includes a very quick and fair peer-review system, which is all easy to use. Visit http://www.dovepress.com/ testimonials.php to read real quotes from published authors. 